Maurer School of Law: Indiana University

Digital Repository@Maurer Law

Indiana Law Journal

Volume 91 | Issue 2

Article 5

Winter 2016

\title{
Rethinking Employment Discrimination Harms
}

Jessica Roberts

University of Houston Law Center, jrobert6@central.uh.edu

Follow this and additional works at: https://www.repository.law.indiana.edu/ilj

Part of the Civil Rights and Discrimination Commons, Labor and Employment Law Commons, and the Law and Race Commons

\section{Recommended Citation}

Roberts, Jessica (2016) "Rethinking Employment Discrimination Harms," Indiana Law Journal: Vol. 91 : Iss. 2 , Article 5.

Available at: https://www.repository.law.indiana.edu/ilj/vol91/iss2/5

This Article is brought to you for free and open access by the Law School Journals at Digital Repository @ Maurer Law. It has been accepted for inclusion in Indiana Law Journal by an authorized editor of Digital Repository @ Maurer Law. For more information, please contact rvaughan@indiana.edu.

\section{$\Psi$}

JEROME HALL LAW LIBRARY

INDIANA UNIVERSITY

Maurer School of Law
Bloomington 


\title{
Rethinking Employment Discrimination Harms
}

\author{
JESSICA L. ROBERTS*
}

Establishing harm is essential to many legal claims. This Article urges the law to adopt a more expansive notion of the harms of employment discrimination to better reflect the cognitive functions of individuals who face discrimination. While the effect of implicit bias on the mental state of potential discriminators is well-worn territory in antidiscrimination scholarship, little has been written about a sister theory: stereotype threat. More than a decade's worth of social psychology research indicates that when a person is conscious of her membership in a particular group and the group is the subject of a widely recognized stereotype, that awareness can directly affect her performance of stereotype-related tasks, creating a self-fulfilling prophecy. For example, a common gender stereotype holds that women are not as good at math as their male counterparts. Thus, when asked to indicate sex before a math test, women tend to perform worse. As a result, if an employer draws attention to an employee's protected status, that seemingly harmless act could impact the employee's mental state and, in turn, her job performance. Despite the well-known effects of stereotype threat, this Article is the first to systematically apply that theory to employment discrimination law.

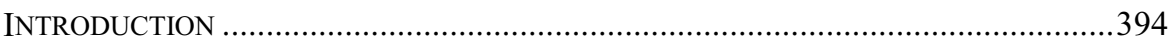

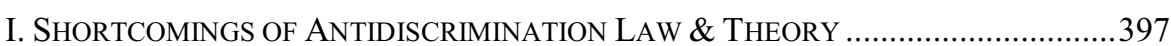

A. FEDERAL EMPLOYMENT DisCRIMINATION PROTECTIONS ..........................397

B. SECOND-GENERATION DISCRIMINATION \& COGNITIVE FUNCTION...........401

II. EFFECT OF STEREOTYPE THREAT ON EMPLOYMENT.........................................404

A. INTRODUCTION TO STEREOTYPE THREAT .........................................405

B. STEREOTYPE THREAT \& JOB PERFORMANCE .........................................409

III. HARM AS A BASIS FOR LAW-MAKING ...........................................................416

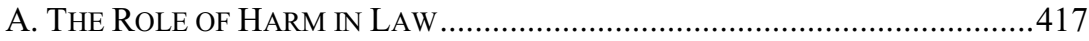

B. CURRENT ANTIDISCRIMINATION HARMS .............................................423

C. STEREOTYPE THREAT TRIGgERS AS HarmfUL .....................................428

IV. TOWARD EXPANDED EMPLOYMENT DISCRIMINATION HARMS ......................434

A. WHY EXPAND EMPLOYMENT DISCRIMINATION HARMS ..........................435

B. BEYOND THE ADVERSE EMPLOYMENT ACTION .....................................438

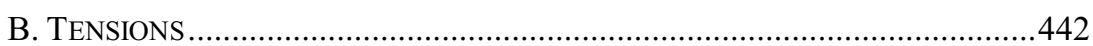

C. Role of LAW IN DECREASING StEREOTYPE THREAT ...............................448

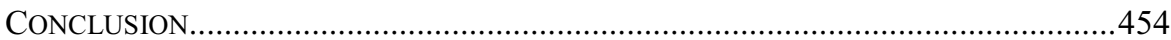

$\dagger$ Copyright (C) 2016 Jessica L. Roberts.

* Associate Professor of Law and Director of the Health Law \& Policy Institute, University of Houston Law Center. My appreciation goes to Jessica Clarke, David Dow, David Fagundes, Tristin Green, Wendy Greene, Jerry Kang, D. Theodore Rave, Kerri Stone, Ron Turner, Howard Wasserman, and the participants of the 2014 Labor and Employment Law Colloquium, the FIU Faculty Workshop Series, and the University of Houston Works-inProgress series. Thank you also to Emily Lawson for outstanding library assistance and to Elaine Fiala for administrative support. Finally, many thanks to the editors of the Indiana Law Journal for their tireless efforts, especially Nicki Hewell. 


\section{INTRODUCTION}

In 2014, Title VII- the Civil Rights Act's landmark employment discrimination provision-turned fifty. ${ }^{1}$ Like all significant milestones, Title VII's golden anniversary provided an opportunity to reflect, spawning an abundance of law review articles, speeches, and symposia. ${ }^{2}$ Yet while we in the antidiscrimination community paused to consider the tremendous strides this law had made, we could not deny that disparities in employment stubbornly persist. ${ }^{3}$ To be sure, Title VII and the employment discrimination statutes it inspired have done important work to level inequalities. However, twenty-first century employment discrimination differs from the openly sexist, racist, ageist, and ableist regimes of the past. ${ }^{4}$ Present-day inequalities therefore demand a new way of understanding employment discrimination harms.

Over a decade ago, Susan Sturm identified "second generation discrimination" as an explanation for the persistence of inequalities in light of legal regulation. Unlike outright exclusionary and animus-driven first-generation discrimination, second-generation discrimination generates disparities - sometimes unknowingly-from structural, relational, and situational factors. ${ }^{5}$ Cognitive or unconscious bias is one of the factors Sturm cited as contributing to this phenomenon. ${ }^{6}$ Pursuant to this theory, much of the differential treatment that leads to social disparities occurs at an unconscious level as a byproduct of normal human cognitive functioning. ${ }^{7}$ Social scientists, ${ }^{8}$ human resources

1. Title VII, Civil Rights Act of 1964, 42 U.S.C. $§ 2000$ e (2012).

2. For example, several law reviews published articles and hosted live events in honor of the Civil Rights Act's fiftieth anniversary. See, e.g., AALS Symposium on the 50th Anniversary of the Civil Rights Act, 67 SMU L. REV. 229 (2014); Symposium, Civil Rights and Civil Justice: 50 Years Later, 32 LAw \& INEQ. 207 (2014); Symposium, The Civil Rights Act at Fifty, 10 Stan. J. C.R. \& C.L. 159 (2014); Symposium, The Civil Rights Act at Fifty: Past, Present, Future, 66 Stan. L. Rev. 1195 (2014); Symposium, The Meaning of the Civil Rights Revolution, 123 Yale L.J. 2576 (2014); Title VII at Fifty Years: A Symposium, 14 Nev. L.J. 661 (2014); The 50th Anniversary of the Civil Rights Act of 1964: A Written Symposium, 74 LA. L. REV. 1039 (2014).

3. See, e.g., Jenny Bourne, “A Stone of Hope”: The Civil Rights Act of 1964 and Its Impact on the Economic Status of Black Americans, 74 LA. L. REV. 1195 (2014); William M. Wiecek \& Judy L. Hamilton, Beyond the Civil Rights Act of 1964: Confronting Structural Racism in the Workplace, 74 LA. L. REV. 1095 (2014).

4. See, e.g., Susan Sturm, Second Generation Employment Discrimination: A Structural Approach, 101 Colum. L. REV. 458, 459-60 (2001).

5. Id. at 460 (explaining that "second generation manifestations of workplace bias are structural, relational, and situational").

6. Id.

7. See Linda Hamilton Krieger, The Content of Our Categories: A Cognitive Bias Approach to Discrimination and Equal Employment Opportunity, 47 STAN. L. REV. 1161 1164-65 (1995); see also infra Part I.B.

8. See Jerry Kang \& Kristin Lane, Seeing Through Colorblindness: Implicit Bias and the Law, 58 UCLA L. REV. 465, 467 (2010) (describing a "recent explosion of scientific knowledge" on implicit bias). 
departments, ${ }^{9}$ journalists, ${ }^{10}$ and legal scholars ${ }^{11}$ alike have embraced this perspective, contemplating the effects of implicit bias and cautioning against its contributions to social inequality.

However, the application of cognitive theory to antidiscrimination law has been largely one-sided. Legal scholars have tended to focus on the mental state of the unwitting discriminator and to ignore the mental state of the individual encountering discrimination. In other words, the writing on cognitive function typically examines how social factors-including current social disparities and widely known stereotypes-influence people's unconsciously held beliefs in a way that could lead them to discriminate despite their best efforts not to. In so doing, it has almost exclusively adopted the cognitive perspective of the discriminator. This imbalance has led to an impressive body of scholarship on the effects of unconscious bias on employers while largely neglecting how those same social factors impact the individuals encountering discrimination. While this particular focus may be understandable given antidiscrimination law's reliance on private enforcement and the importance of intent, it creates a notable asymmetry in our understanding of how discrimination really works.

This Article addresses that asymmetry by exploring the cognitive functioning of people who face discrimination. Researchers have long established that an individual's membership in a particular identity group - when drawn to her attention - can affect her performance on competence-related measures. This phenomenon, known as stereotype threat,$^{12}$ occurs when a member of a group that has been widely stereotyped is reminded of her group membership and then told to

9. See, e.g., February 2015 Workshop-Implicit Bias in the Workplace, N. CounTY HuM. RESOURCES-SAN DIEGO http://www.nchrsd.org/events/event_details.asp?id=590811 [http://perma.cc/H5FG-A5ZY]; Ohio State University Human Resources, The Impact of Implicit Bias, YouTuBE (Apr. 18, 2013), https://www.youtube.com/watch?v=fL9_gD88xk [https://perma.cc/S89N-VDAC].

10. See, e.g., Kare Anderson, Recognize Your Bias to Reduce Your Missteps in Connecting, FORBES (Jan. 14, 2015, 10:06 AM), http://www.forbes.com/sites/kareanderson /2015/01/14/recognize-your-bias-to-reduce-your-missteps-in-connecting/ [http://perma.cc/7JHS -V5PR]; Tim Donovan, White People Are More Racist Than They Realize, Salon (Jan. 16, 2015, 11:31 AM), http://www.salon.com/2015/01/16/white people are more racist than _they_realize_partner/ [http://perma.cc/P2M2-4RSK]; Farhad Manjoo, Exposing Hidden Bias at Google, N.Y. TIMES (Sept. 24, 2014), http://www.nytimes.com/2014/09/25 /technology/exposing-hidden-biases-at-google-to-improve-diversity.html?_r=0 [http://perma.cc /PHJ9-EQPQ].

11. For a discussion of the legal scholarship on implicit bias, see infra notes 53-63.

12. Caryn J. Block, Sandy M. Koch, Benjamin E. Liberman, Tarani J. Merriweather \& Loriann Roberson, Contending with Stereotype Threat at Work: A Model of Long-Term Responses, 39 COUNSELING PSYCHOLOGIST 570, 571 (2011) ("Stereotype threat occurs in a situation where there is an expectation that one may be judged on the basis of social group membership and there is a negative stereotype about one's social identity group." (citation omitted) (citing Steele et al., infra note 67)); Loriann Roberson, Elizabeth A. Deitch, Arthur P. Brief \& Caryn J. Block, Stereotype Threat and Feedback Seeking in the Workplace, 62 J. VocAtional BeHAV. 176, 177 (2003) ("“Stereotype threat' has been defined as the fear of confirming a negative stereotype about one's group through one's own behavior." (citation omitted) (citing Steele \& Aronson, infra note 66)). 
perform an evaluative exercise that implicates a stereotype-related skill. ${ }^{13}$ For example, women and racial minorities tend to score lower on aptitude tests when, prior to testing, they were asked to indicate their race or sex and were told that the test would assess their skill level. Social psychologists postulate that individuals experience stereotype threat not because they believe the associated stereotypes but rather because they fear that their performance will confirm the stereotypic beliefs held by others. Because employment is both important to identity and implicates competence-related skills, individuals may experience stereotype threat at work. Triggering stereotype threat on the job could lead to stress, anxiety, and-most significantly - compromised job performance.

Yet this Article does more than just apply a previously underutilized social psychology theory to employment discrimination. It urges the law to expand what constitutes a legally recognized employment discrimination harm to better reflect the lived experiences of individuals who face discrimination.

Harm occupies a crucial role in legal regulation. As a general matter in the law, plaintiffs cannot recover if they do not demonstrate that they were negatively affected by the defendant's conduct. At present, the adverse employment action is the paradigmatic employment discrimination harm. Adverse employment actions include failing to hire, firing, failing to promote, demoting, and reassigning unfavorably. ${ }^{14}$ With the exception of disparate impact cases, plaintiffs must establish that the employer acted intentionally. The existing literature on implicit bias has, among other things, challenged the feasibility of the intent requirement. This Article instead takes the perspective of the individual facing discrimination by exploring what is construed as harmful. Despite the measurable negative impacts of stereotype threat on job performance, no previous legal scholarship has systematically applied the science of stereotype threat to the field of employment discrimination. ${ }^{15}$

13. For a description of stereotype threat and its consequences, see infra Part II.A. It is also possible that triggering certain stereotypes could have a positive impact on performance. See, e.g., Jennifer Lee, Asian American Exceptionalism and "Stereotype Promise," Soc'Y PAGES (May 4, 2012), http://thesocietypages.org/papers/asian-american-exceptionalism-and -stereotype-promise/ [http://perma.cc/5A2U-EZQ4] (arguing that Asian American students can benefit from "stereotype promise" thereby leading to increased performance).

14. See, e.g., 42 U.S.C. $§ 2000 e-2(a)(1)$ (2012); 29 U.S.C. § 623(a)(1) (2012). Notably, many federal antidiscrimination statutes, such as Title VII, also forbid classifying merely on the basis of a protected status. See 42 U.S.C. $§ 2000$ e-2(a)(2) (2012); 29 U.S.C. § 623(a)(2) (2012).

15. Scholars writing about implicit bias have noted that the intent requirement adversely affects employment discrimination claims. See Krieger, supra note 7; see also Linda Hamilton Krieger \& Susan T. Fiske, Behavior Realism in Employment Discrimination, 94 CAL. L. REV. 97 (2006). Authors have also mentioned stereotype threat in their work on employment discrimination law but only passingly. See, e.g., Samuel R. Bagenstos, Implicit Bias, "Science," and Antidiscrimination Law, 1 HARV. L. \& PoL'y REV. 477, 484 (2007) (referencing "stereotype threat (i.e., that the fear of being labeled a bigot will drive some people to behave in a manner that appears bigoted)"); Tristin K. Green, Racial Emotion in the Workplace, 86 S. CAL. L. REV. 959, 972-73 (2013) (stating that "[r]esearch also suggests that racial minorities are likely to experience anxiety and fear before and during interracial interactions arising out of concerns about being judged according to stereotypes or otherwise confirming commonly held stereotypes about their group" but not referring to that 
This Article therefore makes an important conceptual contribution. By recognizing the effects of stereotype threat, it demonstrates that far more conduct is harmful than traditionally acknowledged. But there are no easy fixes here. To that end, it does not advocate a specific single legal approach for challenging the harms of stereotype threat. Instead, it looks to how the law might intervene to encourage individuals to act in a way that will reduce workplace disparities without overregulating.

The Article consists of four parts. Part I identifies the adverse employment action as the paradigmatic employment discrimination harm and explores the persistence of disparities in employment. It notes the popularity of unconscious bias theories and proposes that the focus on the cognitive functions of discriminators have made previous accounts lopsided. Part II introduces stereotype threat to demonstrate how social factors may impact the cognitive functioning of applicants and employees who fear discrimination. Part III turns to harm as a basis for law-making and applies the harm principle to employment discrimination legislation, asserting that triggering stereotype threat is harmful in a way that justifies legal regulation. Finally, drawing from current legal protections, Part IV urges lawmakers to think beyond adverse employment actions to combat the second-generation discrimination caused by stereotype threat.

\section{SHORTCOMINGS OF ANTIDISCRIMINATION LAW \& THEORY}

Our current employment discrimination system is ineffective. While legislation has effectively targeted intentional, animus-driven exclusion, well-documented inequalities remain. Part I surveys the existing federal protections and identifies the adverse employment action as the primary antidiscrimination harm. It then turns to the ongoing disparities in employment despite these statutes. The Article proffers Sturm's notion of second-generation discrimination as a possible explanation for those continued inequities. It focuses on the immense popularity of cognitive bias theory starting in the mid-1990s and continuing into today. Part I ends by challenging the use of implicit bias in antidiscrimination scholarship as one-sided, focusing primarily on the mindset of the potential discriminator and frequently ignoring how social stereotypes affect the cognitive functions of the individuals who face discrimination.

\section{A. Federal Employment Discrimination Protections}

In 1964, Congress passed the Civil Rights Act. Title VII, which prohibits discrimination on the basis of race, color, religion, sex, or national origin, was among that watershed statute's most significant provisions. Title VII has led to a number of positive changes in employment, ${ }^{16}$ including laying the groundwork for additional

phenomenon as stereotype threat); Kang \& Lane, supra note 8, at 505-06 (discussing the incongruence of opponents of implicit bias who embrace stereotype threat); Jerry Kang, Trojan Horses of Race, 118 HARV. L. REV. 1489, 1521-22 (2005) (describing the presence of stereotype threat and stereotype boost in a study of Asian American women taking challenging math tests).

16. 42 U.S.C. $\S 2000 \mathrm{e}-2(\mathrm{c})(2)$ (2012). For example, black male heads of household saw their wages increase sharply in the 1960s. Bourne, supra note 3, at 1204 fig.4. In the 1970s, 
employment discrimination legislation. Just three years later, the Age Discrimination in Employment Act (ADEA), which prohibits employment discrimination against individuals age forty and over, ${ }^{17}$ became law. Title VII also provided a template for the key employment discrimination provisions in the Americans with Disabilities Act (ADA) ${ }^{18}$ and the Genetic Information Nondiscrimination Act (GINA). ${ }^{19}$ In particular, one attribute all these laws share is adopting the adverse employment action as the paradigmatic employment discrimination harm in need of redress.

\section{Title VII}

As discussed, Title VII was pathbreaking employment discrimination legislation that paved the way for other federal protections. The relevant provision provides that an employer cannot fail to hire, fire, or otherwise discriminate against an applicant or employee on the basis of race, color, religion, sex, or national origin. ${ }^{20}$ It also forbids employers from limiting, segregating, or classifying applicants or employees in a way that would disadvantage them based on those same enumerated grounds. ${ }^{21}$ The prohibited types of conduct are broadly referred to as "adverse employment actions." ${ }^{22}$ They must disadvantage the employee or applicant by denying him an employment opportunity or fair compensation or by "otherwise adversely affect[ing] his status as an employee." ${ }^{23}$

Title VII also allows plaintiffs to recover for certain kinds of unintentional discrimination. However, even claims that do not require intent still require harm. ${ }^{24}$ In disparate impact actions, plaintiffs must prove that the employer's facially neutral policy had a disproportionately negative effect on the impacted group. ${ }^{25}$ Similarly, in a pattern or practice case, the federal government, through either the Equal Employment Opportunity Commission (EEOC) or through the Attorney General, can

sex segregation in employment also began dropping. Barbara F. Reskin \& Irene Padavic, Sex, Race, and Ethnic Inequality in United States Workplaces, in HANDBOOK OF SOCIOLOGY OF GENDER 343, 345 (Janet Saltzman Chafetz ed., 2006).

17. 29 U.S.C. $\S 631$ (a) (2012) ("The prohibitions in this chapter shall be limited to individuals who are at least 40 years of age.").

18. 42 U.S.C. $\S 12112$ (a) (2012).

19. 42 U.S.C. $\S 2000 \mathrm{ff}-1$ (a) (2012).

20. 42 U.S.C. $\S 2000 \mathrm{e}-2(\mathrm{a})(1)(2012)$.

21. 42 U.S.C. $\S 2000 \mathrm{e}-2(\mathrm{a})(2)(2012)$.

22. 8 Employment CoOrdinator EMPloyment Practices $\S 107: 45$ (defining "adverse employment action").

23. 42 U.S.C. $\S 2000 \mathrm{e}-2(\mathrm{a})(2)$.

24. 2 LeX K. LARSOn, EMPLOYMENT Discrimination $\S 20$ (2d ed. 2015) (explaining that claims for disparate impact cover neutral practices with discriminatory effects). The need to establish a discriminatory impact can be framed as a harm requirement.

25. After a plaintiff has shown a disparate impact, the defendant must demonstrate that the challenged policy is job-related and consistent with business necessity. See 42 U.S.C. $\S 2000 \mathrm{e}-2(\mathrm{k})(1)(\mathrm{A})(\mathrm{i})$ (2012). If the employer meets that burden, the employee can still prevail by showing an alternative employment practice. See 42 U.S. $\S 2000 \mathrm{e}-2(\mathrm{k})(1)(\mathrm{A})(\mathrm{ii})$ (2012) ("[T]he complaining party makes the demonstration described in subparagraph (C) with respect to an alternative employment practice and the respondent refuses to adopt such alternative employment practice.”); Griggs v. Duke Power Co., 401 U.S. 424 (1971). 
sue employers directly for systematic discrimination. ${ }^{26}$ To prevail, the government must establish that the employer's conduct formed a pattern of discrimination or was part of the employer's standard operating procedure, thereby inferring discrimination from statistics and individual cases. ${ }^{27}$ To succeed in both pattern or practice and individual disparate impact actions, the government or plaintiffs, respectively, must demonstrate categorical exclusion or disadvantage on the basis of the protected status. The question is not whether the employer intended to discriminate on the basis of protected status but rather whether the employee experienced an employment harm on that basis. $^{28}$

\section{Age Discrimination in Employment Act}

The ADEA includes a similar ban on adverse employment actions. It adopts language similar to Title VII's antidiscrimination and anticlassification prohibitions and adds a provision that forbids employers from "reduc[ing] the wage rate of any employee in order to comply with this chapter." ${ }^{29}$ Consequently, just as in claims for race- or sex-based discrimination, age discrimination plaintiffs must establish that they experienced an employment-related harm. Like Title VII, the ADEA allows claims for disparate impact, as well as for pattern and practice. ${ }^{30}$

Importantly, however, the ADEA departs from Title VII with respect to the scope of its coverage. Title VII makes any consideration of the enumerated protected statuses actionable. The statute protects people of all races. ${ }^{31}$ Conversely, the ADEA offers asymmetrical protection. It forbids only discrimination on the basis of age that

26. 42 U.S.C. $\S$ 2000e-6(a) (2012); see also 1 LEX K. LARSON, EMPLOYMENT DISCRIMINATION $\S 8.01(3)$ ( 2 d ed. 2015).

27. See United States v. City of Yonkers, 609 F. Supp. 1281, 1285 (S.D.N.Y. 1984) ("[A] pattern of discrimination might be proved by either widespread disparate impact or regular disparate treatment.").

28. See ZAMIR \& MedinA, infra note 206, at 246-47. However, not all scholars root prohibitions on unintended discrimination in terms of the harm principle. See generally Gardner, infra note 169 (locating the source of legitimacy for laws banning "indirect discrimination" predominately in a theory of distributive justice rather than in harm but acknowledging the symbiosis between the two for purposes of antidiscrimination legislation).

29. Compare 29 U.S.C. $\S 623$ (a) (2012) (relevant ADEA prohibitions), with 42 U.S.C. $\S 2000 \mathrm{e}-2$ (a) (2012) (relevant Title VII prohibitions).

30. However, these claims operate slightly different with respect to the ADEA. While the Supreme Court held that ADEA plaintiffs could recover under a disparate impact theory, Smith v. City of Jackson, 544 U.S. 228, 228 (2005), the ADEA contains a provision not present in Title VII that allows employers "to take any action otherwise prohibited under subsections (a), (b), (c), or (e) of this section where age is a bona fide occupational qualification reasonably necessary to the normal operation of the particular business, or where the differentiation is based on reasonable factors other than age . . ," 29 U.S.C. $§ 623(\mathrm{f})(1)$, creating a defense to disparate impact actions specific to the ADEA. Thus, while Title VII requires business necessity, ADEA defendants need only establish reasonableness. Although the ADEA does not contain a specific pattern and practice provision like Title VII, the government has brought such claims. 8 LEX K. LARSON, EMPLOYMENT DisCRIMINATION $§ 137.02(3)$ (2d ed. 2015).

31. See McDonald v. Santa Fe Trail Transp. Co., 427 U.S. 273, 283 (1976) (applying Title VII to all races). 
adversely impacts one class of individuals, people who are over forty, not discrimination on the basis of age generally. ${ }^{32}$

\section{Americans with Disabilities Act}

Title I of Americans with Disabilities Act, like Title VII and the ADEA, also adopts a ban on adverse employment actions. It prohibits employers from "discriminat[ing] against a qualified individual on the basis of disability in regard to job application procedures, the hiring, advancement, or discharge of employees, employee compensation, job training, and other terms, conditions, and privileges of employment." ${ }^{33}$ Further, the ADA, like the ADEA, is asymmetrical. It only protects individuals with disabilities. ${ }^{34}$ Additionally, the ADA allows plaintiffs to recover for both intentional and unintentional discrimination on the basis of disability. ${ }^{35}$ However, disability may affect job performance in ways that other protected statuses might not, making it arguably more relevant to employment. Further, the law is designed not only to prevent discrimination on the basis of disability but also to facilitate accommodation, which requires differential treatment. ${ }^{36}$ The ADA therefore simultaneously offers both more and less employment discrimination protections than its predecessors. It offers more protection insofar as it requires accommodation but less insofar as it acknowledges that disability could have an effect on a person's ability to perform at least some job functions.

32. Yet while individuals under forty have no protection, if a policy adversely affects anyone over forty the conduct may be actionable. See 29 C.F.R. $\S 1625.2$ (2014).

33. 42 U.S.C. § 12112(a) (2012).

34. See 9 Lex K. LARSOn, EMPloyment Discrimination $§ 154.01$ (2d ed. 2015) ("[T] $[\mathrm{here}$ is no counterpart to the 'reverse discrimination' protection offered by statutes such as Title VII; only discrimination against disabled individuals is prohibited." (footnote omitted)).

35. The ADA explicitly authorizes claims for disparate impact. See 42 U.S.C. $\S 12112$ (b)(3)(A) (2012) (“[Prohibited discrimination includes] utilizing standards, criteria, or methods of administration ... that have the effect of discrimination on the basis of disability ....”); id. § 12112(b)(6) (“[Prohibited discrimination includes] using qualification standards, employment tests or other selection criteria that screen out or tend to screen out an individual with a disability or a class of individuals with disabilities unless the standard, test or other selection criteria, as used by the covered entity, is shown to be job-related for the position in question and is consistent with business necessity ....").

36. The very nature of reasonable accommodation requires treating people with disabilities differently. See 42 U.S.C. § 12111(9)(B) (2012) (“[R]easonable accommodation may include . . . job restructuring, part-time or modified work schedules, reassignment to a vacant position, acquisition or modification of equipment or devices, appropriate adjustment or modifications of examinations, training materials or policies, the provision of qualified readers or interpreters, and other similar accommodations for individuals with disabilities."); see also Samuel R. Bagenstos, Subordination, Stigma, and "Disability," 86 VA. L. ReV. 397 , 457 (2000) (calling the accommodation requirement "a mild regime of affirmative action"). 


\section{Genetic Information Nondiscrimination Act}

Now turning to the fourth and final major federal employment discrimination legislation, the Genetic Information Nondiscrimination Act. GINA also draws heavily from previous legislation, prohibiting adverse employment actions on the basis of genetic information. It returns to the familiar structure of Title VII and the ADEA, banning employers from failing to hire, firing, or otherwise discriminating against an individual on the basis of genetic information and from limiting, segregating, or classifying employees in a way that would disadvantage them based on their genetic information. ${ }^{37}$ However, while GINA mirrors Title VII on its face, at present the new law specifically excludes claims for disparate impact ${ }^{38}$ but provides that Congress will revisit this issue six years after the statute's enactment. ${ }^{39}$

In sum, Title VII, the ADEA, the ADA, and GINA cover different kinds of protected statuses and operate in different ways. Yet while the current federal employment discrimination protections may vary according to their subject and scope, they share a single unified characteristic: a prohibition on harmful, employment-related conduct on the basis of the protected status and statutory relief specifically tailored to prevent and redress those particular kinds of antidiscrimination harms.

\section{B. Second-Generation Discrimination \& Cognitive Function}

Congress passed Title VII in response to the deliberate and overt exclusion and subordination of women and people of color. ${ }^{40}$ Not surprisingly then, Title VII and its progeny focus primarily on intentional adverse employment actions. Although first-generation causes of discrimination have not disappeared, much of the intentionally and facially discriminatory employment practices of the past have faded in the wake of civil rights laws. ${ }^{41}$ Yet even with the proliferation of federal employment discrimination statutes, workplace disparities still remain. ${ }^{42}$ Racial wage and employment gaps persist, with employed black men earning $23 \%$ less than employed white men of similar age and educational level. ${ }^{43}$ Further, nearly one-third of black, male household heads between ages twenty to sixty do not participate in the labor market. ${ }^{44}$ Similarly, one-third of American women teeter on the edge of

37. 42 U.S.C. $\$ 2000 \mathrm{ff}-1$ (a) (2012).

38. Id. $\S 2000 \mathrm{ff}-7(\mathrm{a})$.

39. Id. $\S 2000 \mathrm{ff}-7$ (b).

40. See Sturm, supra note 4, at 465-66; cf. Tristin K. Green, Discrimination in Workplace Dynamics: Toward a Structural Account of Disparate Treatment Theory, 38 HARV. C.R.-C.L. L. REV. 91, 95 (2003) (explaining that when Title VII was enacted, discrimination was primarily thought of in terms of overt racism or sexism).

41. See Sturm, supra note 4, at 459-60; see also id. at 465-68 (describing how employment discrimination law evolved to target first-generation concerns).

42. See Sandra F. Sperino, Rethinking Discrimination Law, 110 Mich. L. ReV. 69, 83 (2011) (noting that "[s]ex and race discrimination are unfortunately still present").

43. Bourne, supra note 3, at 1197.

44. Id. 
poverty. ${ }^{45}$ This outcome is likely the result of more women becoming heads of household coupled with a stubborn gender pay gap and the concentration of women in low-wage "pink-collar" jobs. ${ }^{46}$ The same holds true in the contexts of age and disability discrimination. For example, after sending resumes to various employers, researchers found that older women were less likely to get a positive response or an interview. ${ }^{47}$ And older workers are the group most likely to face long-term unemployment. ${ }^{48}$ Likewise, a mere $18 \%$ of working-age people with disabilities are employed - as compared to $64 \%$ of working-age people without disabilities - and of those individuals with disabilities who do work, they have comparatively lower status jobs and make less money. ${ }^{49}$ Employment discrimination scholars have puzzled over the stubbornness of employment inequalities despite legal regulation for decades.

Sturm's theory of second-generation discrimination offers one very popular explanation. She has proposed that "[c]ognitive bias, structures of decisionmaking, and patterns of interaction have replaced deliberate racism and sexism as the frontier of much continued inequality." ${ }^{50}$ Put differently, current workplace disparities are not the result of discriminatory animus, or even conscious stereotyping, but the consequences of the interplay of a variety of social and psychological factors. Moreover, second-generation discrimination is cumulative: no single event is responsible for the resulting inequities. Instead, forces operate incrementally, producing disparities and exclusion over time. ${ }^{51}$ As a result, she asserts that "the first generation form of regulation [with its focus on discriminatory intent and adverse employment actions] is inadequate to address the complexities of second generation bias. ${ }^{52}$

Implicit bias is a notorious source of second-generation discrimination. Even before Sturm published her seminal paper on second-generation discrimination, authors were exploring the effect of unconscious bias on employment. Linda Hamilton Krieger pioneered the application of cognitive psychology to employment discrimination law in her now-famous 1995 article, The Content of Our Categories: A Cognitive Bias Approach to Discrimination and Equal Employment Opportunity. ${ }^{53}$

45. See Tyjen T. Conley, 1 in 3 Women in the U.S. Hover Between Poverty and the Middle Class, Population Reference Bureau (Apr. 2014), http://www.prb.org/Publications /Articles/2014/shriver-report-poverty.aspx [http://perma.cc/6538-MEHG] (discussing MARIA Shriver \& the Center for American Progress, The Shriver Report: A Woman's Nation Pushes BACK From the BrinK (Olivia Morgan \& Karen Skelton eds., 2014).

46. See id.

47. See David Neumark, Aarp Pub. Policy Inst., Reassessing the Age DiscriminATION In EMPLOYMENT ACT 14-16 (2008).

48. Susan Bisom-Rapp \& Malcolm Sargeant, Diverging Doctrine, Converging Outcomes: Evaluating Age Discrimination Law in the United Kingdom and the United States, 44 Loy. U. CHI. L.J. 717, 766 (2013).

49. See Michelle Maroto \& David Pettinicchio, The Limitations of Disability Antidiscrimination Legislation: Policymaking and the Economic Well-Being of People with Disabilities, 36 L. \& POL'Y 370, 371 (2014).

50. Sturm, supra note 4 , at 460 .

51. See id.

52. Id. at 478 .

53. See Krieger, supra note 7. 
Therein she proposes that a significant amount of current disparities in employment are simply byproducts of normal human cognitive functioning ${ }^{54}$ specifically (1) the mind's proclivity for categorizing by type (i.e., stereotyping in the value-neutral sense), (2) the tendency of those stereotypes to affect judgment and decision making, and (3) the ability of those stereotypes to operate outside the conscious self-awareness of the individual decisionmaker. ${ }^{55}$ These processes are so automatic that many individuals are surprised to learn of their own implicit biases ${ }^{56}$ Hence, Krieger identifies Title VII's primary shortcoming as "the assumption that disparate treatment discrimination, whether conscious or unconscious, is primarily motivational, rather than cognitive, in origin. ${ }^{" 57}$ By requiring disparate treatment plaintiffs to establish discriminatory intent, ${ }^{58}$ the current law not only undermines their claims - because so much cognitive function occurs implicitly and therefore absent a clear, conscious motivation that a plaintiff can prove before a court-but also runs the risk of exacerbating intergroup tensions. ${ }^{59}$

Initially, employment discrimination theory focused on the bad motives of specific individuals. ${ }^{60}$ However, critiques of the intentional account of employment discrimination law have caused a number of scholars to embrace cognitive bias as a lens, both for understanding how current employment discrimination works and for proposing reforms. For example, Christine Jolls and Cass Sunstein advocate "debiasing" as a potential function of antidiscrimination law, including affirmative action. ${ }^{61}$ Other scholars, such as Susan Sturm and Tristin Green, have called for structural accounts of employment discrimination law and theory, pushing lawmakers and scholars to consider how social, organizational, and cognitive factors generate discrimination. ${ }^{62}$ Finally, Jerry Kang and Kristin Lane have advocated a "behavioral realist" understanding of the law, seeking to reconcile legal constructs with the most recent scientific understandings of human cognition and behavior. ${ }^{63}$

54. Id. at 1187.

55. See id. at $1187-88$.

56. Christine Jolls \& Cass R. Sunstein, The Law of Implicit Bias, 94 CAL. L. REV. 969, 975 (2006).

57. Krieger, supra note 7, at 1164.

58. See Tex. Dep't of Cmty. Affairs v. Burdine, 450 U.S. 248, 253 (1981) ("The ultimate burden of persuading the trier of fact that the defendant intentionally discriminated against the plaintiff remains at all times with the plaintiff."); see also Theresa M. Beiner, The Trouble with Torgerson: The Latest Effort to Summarily Adjudicate Employment Discrimination Cases, 14 NEV. L.J. 673, 674-75 (2014) ("With the exception of disparate impact cases, all employment discrimination cases require a plaintiff to show the state of mind of the defendant-employer, or of one or more of its employees." (footnote omitted)); Green, supra note 40, at 112 ("Disparate treatment doctrine has long been understood to require a showing of intentional discrimination, often defined in terms of conscious motivation to discriminate.").

59. See Krieger, supra note 7, at 1165.

60. Cf. Melissa Hart, Subjective Decisionmaking and Unconscious Discrimination, 56 ALA. L. REV. 741, 745 (2005) (describing how courts' initial interpretations of Title VII reflected a view of early twentieth century psychologists and social theorists that prejudice is a psychopathology, not an extension of normal cognitive processes).

61. Jolls \& Sunstein, supra note 56, at 977.

62. See Green, supra note 40, at 92; Sturm, supra note 4, at 462.

63. See Kang \& Lane, supra note 8, at 490-91. Additionally, the California Law Review 
Undoubtedly, legal scholars have devoted considerable energy to addressing second-generation discrimination. However, as Sturm herself notes, "[T]he 'wrong' of second generation discrimination cannot be reduced to a single, universal, or simple theory of discrimination." ${ }^{4}$ The impressive literature on implicit bias only tells one side of the story. While I agree with my colleagues that understanding the cognition of even well-intentioned employers and coworkers is essential to eliminating second-generation discrimination, I also believe that this approach is incomplete. It focuses primarily on the way in which psychosocial factors impact the cognitive functions of potential discriminators without accounting for the effects of those same forces on the individuals who face discrimination. Even without a rigorous intent requirement, an employee has no cause of action if her employer takes a harmful action that does not immediately result in an adverse employment action. These small actions may accrue to produce the very workplace disparities that the current law is unable to address. Thus, to eliminate second-generation discrimination, our laws must also account for conduct that is harmful to reflect the lived experiences of the people facing discrimination. Properly understanding the role of stereotype threat fills an important gap in the current employment discrimination literature and is a move in the right direction.

Federal employment discrimination statutes focus their protections on the adverse employment action, making it the paradigmatic employment discrimination harm. However, these protections have failed to eliminate disparities in the workplace. Perhaps our current antidiscrimination laws fall short because the nature of discrimination has changed since the 1960s. Second-generation discrimination is the result of structural, relational, and situational factors. Scholars have devoted significant attention to the role of cognitive functioning in perpetuating existing disparities. Yet previous accounts have been largely one-sided, focusing exclusively on the cognition of the discriminator and ignoring how the same social factors could affect individuals who face discrimination.

\section{EFFECT OF STEREOTYPE THREAT ON EMPLOYMENT}

As two social cognition theories, one exploring the mental state of the discriminator and the other exploring the mental state of the object of discrimination, implicit bias and stereotype threat would appear to be two sides of the same coin. Yet while a good deal of recent, thoughtful employment discrimination scholarship has dealt with implicit bias, not nearly as much attention has been paid to stereotype threat. ${ }^{65}$ Focusing solely on the mindset of the employer fails to fully capture the ways in which ordinary cognitive functioning leads to second-generation discrimination. It is crucial to also account for the perspective of the applicant or employee who is vulnerable to discrimination. Understanding stereotype threat reconciles this imbalance. Part II begins with an overview of the psychosocial literature on stereotype threat to provide evidence of the tangible psychological and

devoted its 2006 symposium to behavioral realism. Symposium on Behavioral Realism, 94 CALIF. L. REv. 945 (2006).

64. Sturm, supra note 4 , at 473.

65. See supra note 15. 
performance-based harms individuals experience when they are made conscious of their membership in a stereotyped group. It then applies the concept of stereotype threat to the workplace, arguing that stereotype threat can negatively impact job performance in a variety of contexts.

\section{A. Introduction to Stereotype Threat}

Studies have shown that when there is a widely known stereotype about a particular group and an individual's membership in that group is drawn to her attention, that reminder will affect her ability to perform evaluative tasks. ${ }^{66}$ For example, a common gender-based stereotype maintains that women are not good at math. When researchers took equally able male and female students (undergraduates at the University of Michigan who had scored in the top fifteenth percentile of their entering class on the math portion of the SAT) and gave them a difficult math test, the women tended to underperform. ${ }^{67}$ Believing that this underperformance was the result of psychosocial factors and not actual differences in mathematical ability, social psychologists embarked on a series of experiments to understand this outcome.

One theory to explain this diminished performance holds that reminders of membership in a stereotyped group could generate feelings of insecurity or inferiority, which in turn would impede performance. Social psychologists call this phenomenon "stereotype threat." ${ }^{68}$ Stereotype threat is diminished performance due to an anxiety that one will confirm a preexisting negative stereotype about one's identity group. ${ }^{69}$ While it is not entirely clear how stereotype threat operates, social psychologists hypothesize that the simultaneous awareness of an individual's own group status and the awareness of a stereotypical belief related to that status combine to create enough psychic noise to get in the way of performance under certain challenging conditions. ${ }^{70}$ The presence of this additional outside psychological threat redirects focus away from the task, leading to depleted mental resources and, as a result, underperformance. For stereotype threat to be present, the negative stereotype

66. See, e.g., Catherine Good, Joshua Aronson \& Jayne Ann Harder, Problems in the Pipeline: Stereotype Threat and Women's Achievement in High-Level Math Courses, 29 J. Applied Developmental Psychol. 17 (2008); Claude M. Steele \& Joshua Aronson, Stereotype Threat and the Intellectual Test Performance of African Americans, $69 \mathrm{~J}$. Personality \& Soc. Psychol. 797 (1995).

67. Claude Steele, Steven J. Spencer \& Joshua Aronson, Contending with Group Image: The Psychology of Stereotype and Social Identity Threat, 34 ADVANCES EXPERIMENTAL Soc. PSYCHOL. 379, 380 (2002).

68. See, e.g., id.

69. See Andrew M. Colman, Oxford Dictionary of Psychology 730 (4th ed. 2015) (defining "stereotype threat" as an "[i]mpairment of performance resulting from perceived likelihood of being judged according to a negative stereotype, or fear of acting in a manner likely to confirm the negative stereotype."); Steele \& Aronson, supra note 66, at 797 ("Stereotype threat is being at risk of confirming, as self-characteristic, a negative stereotype about one's group." (emphasis omitted)); see also supra note 12 and accompanying text.

70. See Block et al., supra note 12, at 572-73; Steele \& Aronson, supra note 66, at 797; see also COLMAN, supra note 69 (stating that "[t]he impairment is believed to be caused by physiological arousal or anxiety"); Roberson et al., supra note 12, at 177. 
must be salient to the particular circumstances. ${ }^{71}$ The women in the aforementioned study underperformed in math but not in English because there is a not a corresponding stereotype that women are not good at English. ${ }^{72}$ Groups that face greater degrees of stereotype and stigma are disproportionately hampered by stereotype threat because they are more likely to encounter situations in which a negative stereotype might apply. ${ }^{73}$ Hence, stereotype threat, when triggered, creates a relative disadvantage for victims of potential stigma and stereotype as compared to individuals who are not associated with similar kinds of negative social beliefs.

Stereotype threat "arises from situational cues signaling that a negative stereotype about one of one's social identities is now relevant as a possible interpretation for one's behavior and self in the setting." ${ }^{.74}$ Not every situation will result in stereotype threat. The stereotype must be activated. Practically speaking, this situational dependency means that stereotype threat can be turned on and off. For instance, researchers found that women did not experience diminished performance when they were told that the difficult math test they were taking did not produce any meaningful gender differences. ${ }^{75}$ Moreover, competing stereotypes can be triggered within the same individuals. One study of Asian American women taking a difficult math test demonstrated that the subjects who had their Asian identities triggered performed best, the subjects with no trigger came next, and the subjects who had their female identity triggered performed the worst. $^{76}$ The ability to activate and deactivate stereotype threat shows that the underperformance does not reflect actual ability but rather external factors.

Importantly, one need not believe the stereotype to be affected: even if the individual herself does not hold a negative belief regarding her status, her consciousness of the perceived significance of the stereotyped status can undermine her confidence nonetheless. ${ }^{77}$ Stereotype threat is thereby self-evaluative: it stems from the subject's own evaluative anxiety that others will judge her based on the relevant stereotype. ${ }^{78}$ Stereotype threat is simply the fear of confirming a stereotype, irrespective of the objective or subjective merit of that stereotype. Sadly, the result

71. See Loriann Roberson \& Carol T. Kulik, Stereotype Threat at Work, 21 ACAD. MGMT. PERSP. 24, 27 (2007) ("[S]ubtle contextual variations (a slight wording difference in the way a test is described, for example) may be enough to make the stereotype salient and disrupt performance."); see also COLMAN, supra note 69; Roberson et al., supra note 12, at 177; Steele \& Aronson, supra note 66, at 797.

72. Steele et al., supra note 67, at 380.

73. See, e.g., Steele \& Aronson, supra note 66, at 797, 799.

74. Steele et al., supra note 67 , at 389.

75. Id. at 381 .

76. Kang, supra note 15 , at 1492-93.

77. Steele \& Aronson, the creators of the term "stereotype threat," have explained: This threat can befall anyone with a group identity about which some negative stereotype exists, and for the person to be threatened in this way, he need not even believe the stereotype. He need only know that it stands as a hypothesis about him in situations where the stereotype is relevant.

Steele \& Aronson, supra note 66, at 798; see also Block et al., supra note 12, at 572; Roberson et al., supra note 12, at 177; Steele \& Aronson, supra note 66, at 797.

78. See Steele \& Aronson, supra note 66, at 797 (describing stereotype threat as "selfevaluative threat"); see also Roberson et al., supra note 12, at 177. 
is that an individual will still experience stereotype threat even though she is completely cognizant that the underlying stereotype itself is inaccurate.

Interestingly, a certain level of difficulty must be present to activate stereotype threat. Although the female students in the study underperformed in the difficult math trial, they did not underperform in an easy math variation. ${ }^{79}$ Researchers have speculated that becoming frustrated with a particular task may be sufficient to activate a relevant negative stereotype because the subject will look for explanations as to why she is struggling and the stereotype will inevitably come to mind as a possible explanation. ${ }^{80}$ Whereas nonstereotyped individuals might attribute task difficulty to a bad day and be concerned that their evaluator could think they are slacking, people who fear being stereotyped have the added concern that should they underperform, their poor outcomes could confirm the underlying stereotype. ${ }^{81}$

Additionally, to experience stereotype threat, someone must be invested in the particular sphere in which she is being evaluated. ${ }^{82}$ That is to say, her self-concept and self-esteem must be tethered to her performance. Otherwise, she would not care whether she confirmed or disproved a stereotype and would not experience the negative arousal necessary to interfere with her cognitive functioning. From a practical perspective, people are more invested when they are good at something, making the most capable or talented individuals likewise the individuals most vulnerable to stereotype threat. ${ }^{83}$ Because of the psychological value placed on performance within the relevant sphere, reactions to stereotype threat include disengagement (and perhaps eventually disidentification) from the relevant domain, self-handicapping to provide an alternate explanation for lowered performance, and working harder to attempt to disprove the stereotype ${ }^{84}$ At least at first, many of the groups studied preferred to attribute their underperformance to individual factors — over which they could assert some measure of control — rather than outside discrimination or stereotyping — over which they could not. ${ }^{85}$

Research has detected the presence of stereotype threat in a variety of groups and with respect to different kinds of assays, including women taking math tests, black students taking standardized tests, Latino students taking standardized tests, and female MBA students performing negotiation exercises. ${ }^{86}$ The adverse effects of stereotype threat are well-documented.$^{87}$ The question is therefore not whether stereotype threat exists but instead which conditions trigger it. ${ }^{88}$

79. Steele et al., supra note 67 , at 380 .

80. For a discussion of frustrating tasks as a potential trigger for stereotype threat, see infra note 93 and accompanying text.

81. See Roberson \& Kulik, supra note 71, at 30.

82. See id. at 31 .

83. See id.; Roberson et al., supra note 12, at 178.

84. See Block et al., supra note 12, at 573.

85. Id. at $575-76$.

86. See id. at 572 .

87. Over 300 peer-reviewed articles have been published on stereotype threat since the concept's inception in 1995. Id. at 571-72. For a very detailed account of the research and conclusions associated with stereotype threat, see generally Steele et al., supra note 67.

88. See Steele et al., supra note 67, at 389-90 (describing stereotype threat as "situational"). 
Several factors have been found to activate stereotype threat in research settings. ${ }^{89}$ Stereotype triggering conditions have included things such as indicating the pertinent identity before a test ${ }^{90}$ being in a demographic minority of the subjects (i.e., token status), ${ }^{91}$ watching a commercial that depicts the relevant stereotype, ${ }^{92}$ or sometimes just taking a frustrating test if it is very likely that poor performance could be attributed to the stereotype. ${ }^{93}$ Stereotype threat teaches us that the mere act of calling attention to relevant identity categories could have an independent impact on mental state and consequently task performance, regardless of any additional — or explicitly discriminatory-conduct.

As noted, groups who commonly experience stereotype threat include many of the populations intended to be the beneficiaries of traditional antidiscrimination legislation, including racial and ethnic minorities, women, older people, and people with disabilities. ${ }^{94}$ These individuals have been described as "stigma conscious." 95 That is, they are especially aware of the widely held negative stereotypes associated with their particular group or trait. This heightened awareness makes them more susceptible to stereotype threat because the relevant stereotype is more readily accessible in their consciousness. As a result, seemingly innocuous actions could arouse awareness of the stereotype in those particular individuals, thereby triggering a stereotype threat reaction. ${ }^{96}$

To sum up, stereotype threat has three key components: (1) a challenging evaluative endeavor (or endeavors) in a domain about which the subject cares, (2) a relevant stereotype, and (3) a trigger that reminds one of her stereotyped status. While this Article focuses on the kinds of stereotype threat experienced by historically disadvantaged individuals, studies have detected stereotype across several different kinds of groups, including whites and men. ${ }^{97}$ In particular, whites are aware of the stereotype that white people are racist and are, therefore, afraid of confirming this negative stereotype. Ironically, efforts not to appear racist may lead to behaviors that could be construed as discriminatory, such as physical distancing. ${ }^{98}$ Thus, stereotype threat is not unidirectional but rather relational - that is, both whites and nonwhites

89. See Roberson et al., supra note 12 , at 178 .

90. E.g., Steele et al., supra note 67, at 387, 393, 401.

91. See Block et al., supra note 12, at 572; Roberson et al., supra note 12, at 177; Roberson \& Kulik, supra note 71, at 32.

92. E.g., Steele et al., supra note 67, at 393, 401-402.

93. See Steele \& Aronson, supra note 66, at 798-99.

94. See Roberson \& Kulik, supra note 71, at 27.

95. Id. (quoting Joshua Aronson, Michael J. Lustina, Catherine Good, Kelli Keough, Claude M. Steele \& Joseph Brown, When White Men Can't Do Math: Necessary and Sufficient Factors in Stereotype Threat, 35 J. EXPERIMENTAL Soc. Psychol. 29, 41 (1999)).

96. Id.

97. For current research on stereotype threat, see Stereotype Threat, PERCEPTION Inst., http://perception.org/research/stereotype-threat/ [http://perma.cc/54QF-3EE4].

98. See generally Phillip Atiba Goff, Claude M. Steele \& Paul G. Davies, The Space Between Us: Stereotype Threat and Distance in Interracial Contexts, 94 J. PERSONALITY \& SOC. PSYCHOL. 91 (2008) (conducting four studies to investigate the role of stereotype threat in racial distancing behaviors). 
experience it. Consequently, this Article only provides part of the picture of how stereotype threat operates in employment. ${ }^{99}$

\section{B. Stereotype Threat and Job Performance}

Given the evaluative nature of workplace and the presence of relevant stereotypes, stereotype threat is very likely a regular occurrence in many people's working lives. ${ }^{100}$ While much of the initial research into the effects of stereotype threat focused on single, stressful evaluative events, such as high-stakes tests, evidence indicates that stereotype threat also exists in the mundane, day-to-day tasks of every job. ${ }^{101}$ Researchers believe that stereotype threat could offer an underexplored explanation for differential job performance ${ }^{102}$ and, thus, could help us to understand and subsequently reduce group differences in both performing a job and in other outcomes contingent on job performance. ${ }^{103}$

\section{Activating Stereotype Threat}

Employment presents exactly the kinds of situations that create stereotype threat. First, work is inherently evaluative. Applicants may be required to take aptitude tests or entrance exams that mirror the conditions of many of the stereotype threat studies. After hiring, employers judge the performance of their employees in any number of ways: hours billed, product moved, customers satisfied, and more. ${ }^{104}$ While small degrees of anxiety can increase job performance, the added stereotype threat could be severe enough to interfere. ${ }^{105}$ Because stereotype threat requires that the task at hand be challenging, employees are most likely to experience this phenomenon during so-called "stretch" assignments, projects outside a given employee's immediate skill set that are designed to "stretch" her abilities to allow her to grow by rising to the occasion. ${ }^{106}$ Experts in job design have long advised employers to include challenging components in all jobs to maintain employee interest and engagement and to bypass ennui, as well as to give new hires demanding work to cut

99. For an outstanding exploration of how race-related feelings operate in the workplace for both racial minorities and whites, see generally Green, supra note 15 (proposing workplace conditions that foster positive interracial relationships and productive work environments).

100. Roberson \& Kulik, supra note 71, at 25 ("Because these conditions regularly occur in the workplace, stereotype threat is also likely to be a common part of many people's work experience.").

101. Id.

102. See Roberson et al, supra note 12 , at 177.

103. Id. at 186 (asserting that "stereotype threat has implications for understanding and reducing group differences in job performance and related outcomes").

104. See Roberson \& Kulik, supra note 71, at 25 (noting that "[e]very job involves being judged by other people, whether you are giving a sales presentation to clients, representing your work team at a meeting, or showing your boss your work for some informal feedback").

105. Id. at 25-26.

106. Id. at 31 . 
their teeth. ${ }^{107}$ However, difficult, unfamiliar assignments may be sufficiently frustrating to facilitate stereotype threat. ${ }^{108}$

Second, many negative stereotypes related to ability are relevant in the work setting, such as the belief that women and people of color lack the skills necessary to be successful leaders when compared to their white male counterparts. ${ }^{109}$ Social psychologists, therefore, believe that it is very likely those individuals experience stereotype threat on the job. ${ }^{110}$

This hypothesis has played out in various studies. For example, a black manager told interviewers: "I felt Whites had a lot of negative ideas about Blacks. I felt evaluated when I asked questions. Asking questions became painful for me." ${ }^{111}$ In the context of sex, researchers investigated stereotypes related to assertiveness and gender difference, finding that the individuals who were surveyed believed both that "good negotiators were 'assertive and concerned with personal gain' and that 'men are more likely to be assertive than women," "112 leading study participants to the seemingly logical conclusion that "men are better negotiators than women." 113 Additionally, age also carries with it relevant stereotypes when it comes to work. Take this statement from a marketing manager:

"You can see in someone's eyes when you are first introduced that you're dead in the water just because you're seen as old." Many older managers refer to "the look" on someone's face as they are introduced. A 57 year old accounts supervisor recounted that on meeting someone face to face for the first time, she was told with a tone of disappointment, "Oh, you have such a young voice on the phone." 114

Disability can also be the basis for stereotype threat. For example, upon being told that neuropsychologists have documented cognitive deficits following head injuries, people with a history of head injury experienced diminished performance in tasks related to memory and intellect. ${ }^{15}$ People have thus experienced stereotype threat on the basis of race, sex, age, and disability—four of the major federal antidiscrimination categories.

107. Id.

108. Id.

109. See Block et al., supra note 12, at 572.

110. Id. (stating that it is "[q]uite likely[] [that] women and people of color in the demographic minority at work experience stereotype threat, as [the conditions for stereotype threat] typically pervade their work environments" (citation omitted)).

111. Roberson \& Kulik, supra note 71, at 26 (quoting FlOYD DiCKENS, JR. \& JACQUELINE B. Dickens, The Black Manager: Making it in the Corporate World (1991)).

112. Id. at 30 (emphasis in original) (quoting Laura J. Kray, Adam D. Galinsky \& Leigh Thompson, Reversing the Gender Gap in Negotiations: An Exploration of Stereotype Regeneration, 87 Org. Behav. \& Hum. Decision Processes 386 (2002)).

113. Id.

114. Id. at 26 (citation omitted) (quoting RenEe Blank \& SANDRA SlipP, Voices of Diversity: Real People Talk About Problems and Solutions in a Workplace Where EVERYONE Is NOT ALIKE (1994)).

115. Id. at 28 . 
Studies have thereby documented the presence of work-related stereotype, and by association the potential for stereotype threat, for several of the statuses protected under existing federal employment discrimination legislation, mainly Title VII, the ADEA, and the ADA. But what of GINA? Is there potential for stereotype threat on the basis of genetic information? Yes and no. Genetic information differs from preceding antidiscrimination categories, like race, sex, age, or disability, because it does not yet constitute a lived social category. ${ }^{116}$ As a relatively new phenomenon, most genetic information does not currently have an associated identity group or widely recognized social stigma. ${ }^{117}$ However, stereotype threat could still pose a problem regardless. Research indicates that individuals who take genetic tests will incorporate the results of their tests into their self-concept, creating a sense of genetic identity. ${ }^{118}$ In fact, some individuals report strong negative affect regarding their level of genetic risk. People with heightened genetic risk have described themselves as "flawed," "dirty," and vulnerable. ${ }^{119}$ Those individuals - much like women, members of racial minorities, or older people - might be reminded of their perceived inferiority and therefore perform worse when an employer inquires into their genetic profiles. Furthermore, even if the individual person does not see her status as negative, she might be aware of her employer's perception that she may constitute a liability, which could likewise have a harmful effect. Genetic information could then also be a basis for stereotype threat, albeit an untraditional one.

In addition to involving both evaluations and potential stereotypes, the workplace may present several opportunities to trigger stereotype threat. Potential stereotype threat triggers on the job include being given the option to indicate group membership prior to an aptitude test, encountering stereotypic materials on the job, being asked about group membership, or being concerned about job performance and worried that the stereotype will be blamed. ${ }^{120}$ Workplace culture can also trigger stereotype threat. The mere demographics of the workforce may be sufficient to elicit a stereotype threat response. Specifically, an absence of diversity could heighten the awareness of potential stereotyping for members of underrepresented groups. ${ }^{121}$ Thus, token status can activate stereotype threat. Moreover, certain jobs may have a cultural centeredness, meaning that norms associated with working and succeeding in that particular job environment are associated with a specific identity group. ${ }^{122}$

116. See Jessica L. Roberts, The Genetic Information Nondiscrimination Act as an Antidiscrimination Law, 86 Notre Dame L. ReV. 597, 623 (2011).

117. Id. at 624 .

118. See Robert L. Klitzman, Am I My Genes? Confronting Fate \& Family Secrets IN THE Age OF GENETIC TESTING 169-182 (2012).

119. Id. at 177. Given the adverse psychological effects of learning about genetic risk, Sharona Hoffman has called for heightened privacy protections at work pre-GINA. See Sharona Hoffman, Preplacement Examinations and Job-Relatedness: How to Enhance Privacy and Diminish Discrimination in the Workplace, 49 U. KAN. L. REV. 517, 556-57, 591-92. (2001).

120. These examples, of course, draw from the triggers documented in the studies, see supra notes 90, 92-93.

121. For a discussion of token status as a trigger of stereotype threat, see supra note 91 and accompanying text.

122. Block et al., supra note 12, at 589. 
Employers can signal cultural centeredness in myriad ways, such as lauding distinct skills, styles, or attributes. ${ }^{123}$ Consequently, employees who are not members of the favored identity group may find themselves feeling like outsiders and thereby more vulnerable to stereotype threat. ${ }^{124}$ Employees may therefore react with efforts to "cover" their disfavored identity by adopting the mannerisms of the preferred group. ${ }^{125}$ But these efforts might not be sufficient to counteract the possibility of stereotype threat. For example, consider a workplace that favors a hip, youthful culture. Older employees may try to act within those conventions, that is, they may attempt to "cover" their age by acting like their younger peers, yet they may still feel concerned about judgments based upon their true age. Really, any time attention is drawn to an individual's stereotyped status at work holds the power to activate stereotype threat.

Ironically, people who apply more effort when confronted by stereotype threat may perform worse, so even seemingly objective evaluations may not measure true aptitude. Hence, there is a Greek tragedian element to stereotype threat: the more individuals fight to disprove a given stereotype, the greater the chance they will experience the very diminished performance that could ultimately confirm it. Stereotype threat thus harms employees by hampering their ability to perform to their actual potential. ${ }^{126}$ It harms employers as well because it impedes their ability to extract the maximum output from their employees.

Additionally, much like how the individual experiencing stereotype threat need not believe the relevant stereotype, it likewise does not matter if a particular employer or manager believes the stereotype. So long as the stereotype persists throughout society, employees will remain vulnerable to stereotype threat and its associated underperformance. ${ }^{127}$ Because actual performance declines in the face of stereotype threat, even an employer with the best of intentions who uses objective measures could underevaluate an employee's ability, perhaps eventually leading to an adverse employment action like firing or failing to promote. ${ }^{128}$

Work contains all the essential ingredients to produce stereotype threat: (1) evaluation in a significant domain, (2) the presence of stereotypes related to performance, and (3) many possible reminders of membership in a stereotyped group. While an employer might not be actively or intentionally engaging in discriminatory conduct, stereotype threat could lead to diminished performance and, as a result, subsequent adverse employment actions that relate to race, sex, age, disability, or even genetic information. While the aforementioned psychic harms are very real, it is not these emotional or dignitary concerns that make stereotype threat

123. Id.

124. See id.

125. See Kenji Yoshino, Covering, 111 YALE L.J. 769, 772-74 (2002) (discussing Erving Goffman's theory of assimilation); see also Block et al., supra note 12, at 577 (citing assimilation as one strategy for fending off a stereotype when faced with stereotype threat).

126. Roberson \& Kulik, supra note 71, at 25 ("Research on stereotype threat has shown that societal stereotypes can have a negative effect on employee feelings and behavior, making it difficult for an employee to perform to his or her true potential.").

127. See id.

128. See id. 
problematic. Rather, it is the effect it may have on actual job performance that is most troubling.

\section{Reactions to Stereotype Threat}

Researchers have explored the implications of a number of different reactions to stereotype threat in the workplace, including fending off the stereotype, being discouraged by the stereotype, and being resilient in the wake of the stereotype. ${ }^{129}$ Reactions to stereotype threat can therefore be both motivating and demotivating. For example, individuals who wish to fend off the relevant stereotype could simply vow to disprove it. One black female executive explained, "Black women need to do work that is sterling - not good work, but sterling work - on a consistent basis. Because I was Black and female I always felt like there was a judge out there." 130 But while one reaction to stereotype threat is to simply work harder, as mentioned, research has indicated that increased efforts in response to stereotype threat might actually further diminish performance. ${ }^{131}$ The result could therefore be that individuals experiencing stereotype threat might work harder yet still perform worse, perhaps ultimately leading to discouragement.

Being discouraged by a stereotype has both short- and long-term reactions. In the short-term, an employee might disengage, severing the tie between the stereotype-relevant domain and her self-esteem. ${ }^{132}$ Disengagement preserves self-worth by making it no longer dependent on an individual's performance in that area. ${ }^{133}$ Individuals may adopt two different psychological processes to achieve disengagement: (1) devaluing or (2) discounting. ${ }^{134}$ Devaluation protects self-esteem by making outcomes no longer relevant so that negative feedback does not affect self-evaluation, whereas discounting rejects the negative feedback as invalid. ${ }^{135}$ When research subjects have been aware of a potentially biased measure, disengaging allowed them to keep their self-esteem intact regardless of their performance. ${ }^{136}$ Researchers believe that employees facing stereotype threat at work may also rely on disengagement as a coping mechanism. ${ }^{137}$

Although an effective strategy for maintaining self-esteem, discounting feedback can have wide-ranging effects on the job. Social and organizational psychologists hypothesize that stereotype threat can unwittingly affect performance at work by influencing how the affected individuals seek and use feedback, leading those employees to receive less than ideal levels of guidance from their superiors and

129. Block et al., supra note 12 , at 574-75.

130. Id. at 575-76 (quoting Ella L. J. Edmondson Bell \& Stella M. Nkomo, OuR SeParate Ways: Black and White Women and the Struggle for Professional Identity 145 (2003)).

131. Roberson \& Kulik, supra note 71 , at 25.

132. See Block et al., supra note 12, at 579.

133. Id.

134. Id.

135. Id. at 579-80.

136. Id. at $579-80$.

137. Id. at 580 . 
fellow workers. ${ }^{138}$ People tend to seek feedback in two basic ways: direct inquiry and indirect monitoring. ${ }^{139}$ Direct inquiry involves approaching supervisors and coworkers to directly ask about one's performance, while someone using indirect monitoring will simply covertly observe what happens in the workplace and respond to what she perceives. ${ }^{140}$ However, these two methods are not equally effective. Research demonstrates that employees who use direct inquiry for feedback seeking are more likely to receive higher performance evaluations. ${ }^{141}$ Direct inquiry tends to be more effective because indirect monitoring leaves more open for interpretation and thus misunderstanding. ${ }^{142}$ Despite the relative ineffectiveness of indirect monitoring, employees will rely on this strategy if they anticipate high costs to making direct inquiries. ${ }^{143}$

In addition to relying on suboptimal feedback seeking mechanisms, employees who are vulnerable to stereotype threat may be more likely to ignore the feedback they do receive, judging it to be potentially biased according to the relevant stereotype. Individuals who discount feedback perceive it to be less useful and informative. ${ }^{144}$ As a result, they do not change their behavior accordingly. Failing to take useful suggestions at work can result in the denial of opportunities for advancement and development. ${ }^{145}$ These theories appear to be correct. For example, field researchers found that black managers who experienced stereotype threat were more likely to dismiss organizational feedback, tending instead to evaluate their job performance through self-monitoring. ${ }^{146}$ This tendency could have resulted in those managers missing out on opportunities to improve, which could have resulted in better job performance and further promotion. ${ }^{147}$ Likewise, another study found that black participants who discounted negative feedback also did not take advice for improving their performance, leading researchers to conclude that stereotype threat may ultimately have a negative impact on job performance. ${ }^{148}$ Hence, individuals facing stereotype threat are more likely both to use low-cost feedback seeking and to discount feedback because they are skeptical of the feedback's veracity and the motivations of the individual giving feedback. ${ }^{149}$ Each of these practices could lead employees to underperform at work, thereby negatively impacting their career prospects.

138. See Roberson et al., supra note 12, at 179.

139. Id.

140. Id.

141. Id.

142. See id. at 186.

143. Id. at 179 .

144. Id. at 186 .

145. Block et al., supra note 12, at 582.

146. Roberson \& Kulik, supra note 71, at 32.

147. Id. at 32 (explaining that "a Black employee who is regularly exposed to stereotype threat about his intellectual ability might dismiss performance feedback from his White manager that would have helped him to meet organizational performance expectations and get on the promotion "fast track"').

148. Roberson et al., supra note 12, at 186.

149. Id. at 183 . 
In the longer term, people experiencing stereotype threat will take more drastic measures to cope. Continued disengagement could lead to disidentification. ${ }^{150}$ Whereas disengagement is acute, disidentification is chronic. In particular, people who disengage from a domain may still identify with it, while people who disidentify with a domain permanently distance themselves from it. ${ }^{151}$ Disidentification can likewise lead to withdrawal, which can have further negative impacts on motivation and performance.

Two kinds of withdrawal can result from discouragement due to stereotype threat at work: psychological and behavioral. ${ }^{152}$ Psychological withdrawal refers to the development of unfavorable attitudes toward the job or the employer, leading to lower levels of loyalty, involvement, and satisfaction. ${ }^{153}$ Not surprisingly, individuals experiencing stereotype threat report decreased job satisfaction. ${ }^{154}$ While psychological withdrawal references attitudinal shifts, behavioral withdrawal consists of the behavioral measures people take to avoid participating in the undesirable work setting, such as being late, missing work, or quitting. ${ }^{155}$ Psychological withdrawal could therefore lead to behavioral withdrawal: stereotype threat could generate negative feelings and attitudes toward employment (psychological withdrawal) that could lead an employee to lose her desire to succeed in the workplace and perhaps to eventually leave (behavioral withdrawal). ${ }^{156}$ Significantly, behavioral withdrawal could manifest in lowered job performance and increased absenteeism as the person looks for validation in other spheres. If an employee withdraws from her job to avoid the psychological perils of stereotype threat, she runs the risk of becoming a bad worker. Perhaps most importantly, if she begins trying less and being absent more, those coping behaviors could provide a valid basis for adverse employment actions that would not have occurred absent the underlying presence of stereotype threat.

Even if an employee does not get fired, she could choose to leave her current job because of diminished interest and lowered investment in her work. ${ }^{157}$ This outcome is unfavorable for employers, who have likely invested resources in training or even grooming her. ${ }^{158}$ Researchers have postulated that stereotype threat could be at least

150. See Block et al., supra note 12, at 573; Steele et al., supra note 67, at 409.

151. See Steele et al., supra note 67, at 410-11.

152. Block et al., supra note 12, at 581 .

153. Id.

154. Roberson \& Kulik, supra note 71 , at 33 (explaining that "[s]tereotype threat is also associated with lower job satisfaction"); see also David N. Laband \& Bernard F. Lentz, The Effects of Sexual Harassment on Job Satisfaction, Earnings, and Turnover Among Female Lawyers, 51 InDUS. \& LAB. REL. REv. 594 (1998) (making this point in the context of sexual harassment).

155. Block et al., supra note 12 , at 581 .

156. See id. at 582 .

157. Roberson \& Kulik, supra note 71, at 33 ("That solo female in your engineering group may begin to think that an alternate career path might be preferable.").

158. Id. (calling disidentification "the worst solution" to stereotype threat because it is "costly for both the individual who gives up a valued part of the self, and for the organization that loses an engaged and motivated employee"). 
partially responsible for the higher level of turnover for women and people of color in positions of power. ${ }^{159}$

Freeing individuals from their vulnerability to potential discrimination is a primary objective of employment discrimination law. When functioning properly, those protections enable workers to perform their jobs less fettered by fears of outright discrimination and disadvantage, allowing them to flourish both vocationally and personally. ${ }^{160}$ Yet the flipside may also hold true. Psychologically uncomfortable workplace environments can seriously affect employees across a number of metrics, including job satisfaction and productivity, leading to higher turnover and increased absenteeism. This anxiety and discomfort can translate into diminished investment in one's employment and lowered performance, both of which could eventually lead to denials of employment-related benefits such as firing or failing to promote. While operating via a subtler process, stereotype threat triggers in the workplace eventually produce exactly the negative outcomes that employment discrimination legislation is designed to address.

Stereotype threat occurs when a person who identifies with a stereotyped identity category is reminded of her devalued social status prior to being evaluated based on a skill related to that stereotypical belief. Studies have verified that stereotype threat produces very real reductions in ability, both in research and real-world settings. While the majority of studies related to stereotype threat have centered on discrete challenging tasks, such as high-stakes testing, researchers have also found evidence of stereotype threat in the workplace. When an employer draws attention to an employee's membership in a negatively stereotyped group, that seemingly innocuous action can have a tangible negative impact on the employee's performance. This Article argues that, while not considered traditional adverse employment actions, stereotype threat triggers are nonetheless harmful and should be covered by employment discrimination law.

\section{HARM AS A BASIS FOR LAW-MAKING}

Before asserting that employment discrimination harms should expand to encompass stereotype threat, it is worth exploring the role of harm in the law. Thankfully, this task is relatively easy. Both preventing and rectifying harm are at the heart of many legal protections. However, harm is an abstract concept with several philosophical meanings. For example, a classical utilitarian would argue that any reduction in welfare (i.e., happiness or pleasure) is harmful. ${ }^{161}$ Yet, such a broad construction of harm is not useful as the basis for legal regulation. It would justify far too much intervention. Consequently, this Article adopts John Stuart Mill's account of which types of welfare-reducing behaviors warrant legal protection. Not

159. Block et al., supra note 12 , at 581-82; Roberson \& Kulik, supra note 71 , at 33 (questioning "whether long-term exposure to stereotype threat could be one cause of turnover for women and racial/ethnic minorities in professional and managerial jobs" because "[s]ome studies have found that members of these groups leave jobs at a higher rate than White men").

160. See Ronald Turner, Book Review, 4 U. PA. J. LAB. \& EMP. L. 243, 248 (2001).

161. See Julia Driver, The History of Utilitarianism, in THE StANFORD EnCYClOPEDIA of PhiLOSOPHY (Edward N. Zalta ed., Winter ed. 2014), available at http://plato.stanford.edu /archives/win2014/entries/utilitarianism-history/ [http://perma.cc/4RNQ-82ZC]. 
only does Mill provide a robust theory of the meaning of harm but his work also lays the foundation for a number of areas of the law, such as criminal law and torts. ${ }^{162}$ Relying on Mill restricts the analysis to a subset of welfare-reducing conduct that coincides with accepted legal doctrines.

This Part introduces the harm principle as a ground for law-making and explores how that concept has informed federal employment discrimination law. It then applies the harm principle to stereotype threat triggers in the workplace, arguing that they are harmful because they create real disadvantage.

\section{A. The Role of Harm in Law}

Laws - whether civil or criminal-function as limiting mechanisms on our conduct. Put simply, they tell us what we can and cannot do. Because the government is responsible both for passing and for enforcing laws, generations of legal philosophers have questioned why those governmental bodies have the authority to dictate the behaviors of their citizenry. One widely accepted notion holds that the purpose of law is to protect people. Famously, John Stuart Mill rooted his theory of what constitutes a valid exercise of power (both through government action or through moral dictate) in the concepts of personal liberty and protection from outside harm:

[T]he sole end for which mankind are warranted, individually or collectively, in interfering with the liberty of action of any of their number, is self-protection. That the only purpose for which power can be rightfully exercised over any member of a civilised community, against his will, is to prevent harm to others. ${ }^{163}$

According to Mill, the only legitimate reason to intrude on an individual's autonomy is to circumvent harm to third parties. Although Mill christened his theory "the principle of liberty," it is more popularly known as "the harm principle." ${ }^{164}$ The harm principle is by its nature coercive. It employs the force of law to forbid conduct that is harmful to others. To warrant legal coercion, the state must not be able to achieve the desired result through other means. ${ }^{165}$ As a general matter, Mill expresses a preference for personal liberty over state regulation. The harm principle thus provides the exception to this general rule: it tells us when the scales should tip in the opposite direction, favoring regulation over liberty. The harm principle can

162. See infra notes 203-204 and accompanying text.

163. John StUart Mill, On LiberTy AND UtiLitARIANiSm 12 (Alfred A. Knopf, Inc. 1992) (1859).

164. Id.; see also Madison Powers, Ruth Faden \& Yashar Saghai, Liberty, Mill \& the Framework of Public Health Ethics, 5 Pub. Health Ethics 6, 7 (2012) ("The most frequently quoted except from the famous passage in Mill's On Liberty summarizing the Principle of Liberty asserts that 'the only purpose for which power can be rightfully exercised over any member of a civilized community, against his will, is to prevent harm to others.' This formulation of Mill's Liberty Principle is one that some (but not Mill) call the 'Harm Principle."”) (internal citations omitted).

165. Nils Holtug, The Harm Principle, 5 Ethical Theory \& Moral Prac. 357, 359 (2002). 
therefore be understood as a "necessary but not sufficient condition" for legal regulation. ${ }^{166}$

John Locke espoused a similar position in his Second Treatise on Government, asserting that government exists primarily to prevent harm to the life, liberty, and property of its citizenry. ${ }^{167}$ It is then no surprise that conversations at the Founding cited harm avoidance as a justification for the existence of government and, by association, law. ${ }^{168}$ While preventing harm may not be the sole justification for state action on a particular issue, ${ }^{169}$ it is nonetheless a widely accepted basis for legal regulation. ${ }^{170}$

Yet despite the harm principle's ubiquity and popularity, it has not gone without intense criticism. The most significant of these criticisms is the harm principle's ability to cast practically every activity as potentially harmful and therefore a valid object of legal intervention. Why? Because no conduct occurs in a vacuum. That is to say, our actions inevitably affect those around us. And sometimes those effects will be negative. ${ }^{171}$ Such a broad construction of what constitutes harm quickly embarks on a slippery slope, offering justification for banning any number of seemingly innocuous activities because they could at some point have a negative impact on another person. ${ }^{172}$ Even Mill himself acknowledged the potential expansiveness of such indirect harms. ${ }^{173}$ Hence, the predominant criticism of the harm principle as a liberty-limiting principle is that the exception threatens to

166. Bernard E. Harcourt, The Collapse of the Harm Principle, 90 J. CRIM. L. \& CRIMINOlOgy 109, 114 (1999) (emphasis omitted); Holtug, supra note 165, at 360.

167. John Locke, Two Treatises of Government 368 (Peter Laslett ed., Cambridge Univ. Press 1970) (1690) (arguing that people form governments "for the mutual Preservation of their Lives, Liberties, and Estates") (emphasis omitted).

168. Elizabeth Price Foley, Liberty for All: Reclaiming Individual Privacy in a New Era of Public Morality 45-48 (2006).

169. See Holtug, supra note 165 , at 362 (explaining that legislatures may act with any number of justifications both inclusive and exclusive of preventing harm). Holtug has identified this aspect of the harm principle as "outcome-based." That is, from the perspective of the harm principle, the relevant question is not how the state has justified legal intervention but rather whether legal intervention is justified. $I d$. at 363. Beyond lawmakers, liberal theorists themselves have also recognized alternate grounds to justify legal regulation, such as distributive justice. See, e.g., John Gardner, Liberals and Unlawful Discrimination, 9 OXFORD J. LEG. STUD. 1 (1989). While the harm principle remains popular, some scholars have rejected the harm principle outright as an inconstant and unstable basis for legal regulation. See, e.g., Richard A. Epstein, The Harm Principle-And How It Grew, 45 U. Toronto L.J. 369 (1995); Holtug, supra note 165; Arthur Ripstein, Beyond the Harm Principle, 34 PHIL. \& PuB. AfF. 215 (2006).

170. See Gardner, supra note 169 , at 1 (describing the harm principle as "[t]he most familiar concept associated with liberal theories of legitimacy"); see also Epstein, supra note 169 , at 370 (noting that "the harm principle is also backed by a deep philosophical pedigree").

171. Epstein supra note 169, at 417; Holtug, supra note 165, at 363-64.

172. See Donald A. Dripps, The Liberal Critique of the Harm Principle, 17 CRIM. JUST. Етнісs 3, 10 (1998) (describing a series of seemingly innocent yet harmful conduct); Holtug, supra note 165, at 363 ("As Mill's critics have repeatedly pointed out, it is very seldom that an individual's behavior does not affect others.").

173. See MiLl, supra note 163, at 72 . 
swallow the rule. As one author put it, "the main critical question about the [harm] principle [is] namely: what constitutes harm." ${ }^{174}$ To be useful, the harm principle must have discernible boundaries. ${ }^{175}$ Otherwise, it could infringe on the very personal liberty it seeks to protect. ${ }^{176}$

While not entirely solving the problem, the harm principle, as imagined by Mill, is subject to certain constraints. The Millian harm principle can be broken down into five component parts: (1) act, (2) third party, (3) welfare reduction, (4) causation, and (5) severity.

\section{Act}

The harm principle primarily targets acts, not omissions. ${ }^{177}$ While it is a valid use of state power to forbid individuals from causing direct harm to one another, it is not a likewise valid use of state power to require them to actively prevent harm. Therefore, the harm principle does not generally support a duty to rescue. However, Mill conceded that the consequences of some inaction might be grave enough to warrant regulation. ${ }^{178}$ Meaning that there are occasions in which the state should intervene to compel its citizens to prevent harm. That being said, he recognized such interventions as the exception, not the rule. ${ }^{179}$ Consequently, deciding when the harm principle should extend to omissions is a continued subject of philosophical inquiry. ${ }^{180}$

\section{Third Party}

Moreover, the relevant harm must be to an outside party. The harm principle explicitly rejects paternalism as a justification for the law to intervene. Mill writes:

His own good, either physical or moral, is not a sufficient warrant. He cannot rightfully be compelled to do or forbear because it will be better for him to do so, because it will make him happier, because, in the opinions of others, to do so would be wise, or even right. These are good reasons for remonstrating with him, or reasoning with him, or persuading him, or entreating him, but not for compelling him, or visiting him with any evil in case he do otherwise. ... The only part of the conduct of any one, for which he is amenable to society, is that which concerns others. ${ }^{181}$

174. Holtug, supra note 165 , at 358 .

175. Gardner, supra note 169 , at 1 .

176. Id.

177. See Epstein, supra note 169, at 395-99 (discussing acts versus omissions).

178. MiLL, supra note 163, at 72 .

179. Id.

180. See Epstein, supra note 169, at 396 (stating that "one of the perennial questions of moral and legal philosophy is whether the harm principle should be extended to cover those cases where a person who is in a position to prevent harm to another person, at little or no cost to himself, should be required to do so").

181. MiLL, supra note 163, at 12-13. 
The harm principle is decidedly other-oriented: it focuses on third party harm. It is, therefore, not a proper use of legal regulation to restrict the liberty of an individual to save her from herself. ${ }^{182}$

\section{Welfare Reduction}

Further, when invoking the harm principle to prevent an action that affects a third party, that action must be - for lack of a better word - harmful. While this point may seem obvious, it is worth a moment to dissect what is meant specifically by the word "harm." When a person is harmed, she experiences some kind of setback or disadvantage. Something does not go her way, resulting in a negative impact on her life. She is, therefore, subject to a reduction in welfare. ${ }^{183}$ Yet there is more than one way in which a person's welfare can be reduced. A harmful action that reduces welfare can either increase her negative welfare or decrease her positive welfare. ${ }^{184}$ An action increases negative welfare when it takes a person from a state of relative neutrality to a state of disadvantage or discomfort. ${ }^{185}$ For example, if I walk up to you and punch you in the nose, I have increased your negative welfare by causing you pain. Reductions in positive welfare can also be understood as harmful. A reduction in positive welfare occurs when an action takes away a benefit to which someone was already entitled. ${ }^{186}$ For example, if you won a million dollars but were unable to collect, you have experienced a decrease in positive welfare. You are theoretically no worse off than when you started; however, you have experienced a reduction in your overall welfare by being denied a valid benefit that you were rightfully owed. Admittedly, the line between these two categories of harm may at times blur.

According to the harm principle, the reduction in welfare cannot be constructed ex post to justify a prohibition on troublesome conduct. For example, I cannot deem your otherwise neutral behavior harmful because I am plagued by the concern that

182. This tenet of the harm principle is not without exception. Mill himself admits: [T] he mischief which a person does to himself may seriously affect, both through their sympathies and their interests, those nearly connected with him and, in a minor degree, society at large. When, by conduct of this sort, a person is led to violate a distinct and assignable obligation to any other person or persons, the case is taken out of the self-regarding class, and becomes amenable to moral disapprobation in the proper sense of the term. If, for example, a man, through intemperance or extravagance, becomes unable to pay his debts, or, having undertaken the moral responsibility of a family, becomes from the same cause incapable of supporting or educating them, he is deservedly reprobated, and might be justly punished; but it is for the breach of duty to his family or creditors, not for the extravagance.

Id. at 78. In other words, an individual's self-harm may be so dire that it then creates tangible negative impacts on those around her. Others have gone so far as suggesting that state intervention might be warranted if the harm to oneself is sufficiently severe. See, e.g., Holtug, supra note 165 , at 361 .

183. Holtug, supra note 165 , at 364 .

184. Id. at 369 .

185. Id. at 368 .

186. Id. 
you will do it again or could do it to others. ${ }^{187}$ For instance, if you take a nap in my office chair, you have perhaps violated my privacy and autonomy but not clearly reduced my welfare. ${ }^{188}$ Pursuant to Mill, I cannot allege your conduct is harmful because now every time I leave my office I am concerned you will sleep in my chair without my permission. As a result, for a harm to warrant prohibition it must be an actual harm not manufactured through anxieties related to future or hypothetical conduct.

\section{Causation}

Causation is yet another aspect of the harm principle. To be the subject of regulation, an action must actually cause the other person's reduction in welfare. Hence, there must be a clear link between the restricted action and the resulting harm to justify an infringement on personal liberty in the form of legal liability. ${ }^{189}$ The link between action and harm is so essential that one scholar has proposed that causation is the core value behind the harm principle. ${ }^{190}$ The centrality of causation lends the harm principle an individualized tinge: by requiring a clear nexus between the act and the resultant harm, the harm principle promotes a norm of personal accountability. ${ }^{191}$ It targets specific instances of harmful conduct.

\section{Severity}

Yet not all actual harms are similarly situated. The final—and perhaps most complex - aspect of the harm principle is severity. As one scholar put it, harm for purposes of the harm principle must involve "a minimum quantity of welfare." 192 Mill explicitly excludes reductions in welfare that are purely dignitary in nature from the meaning of harm. He explains:

187. Ripstein, supra note 169 , at 220 ("If my act itself does no harm, then your fear that I will do it cannot bootstrap it into one. ...”).

188. This example of a wrongful act that creates no harm is a variation on the example discussed at length in Ripstein's article: taking a nap in someone's bed while they are not home and without their consent. Id.

189. Donald J. Kochan, On Equality: The Anti-Interference Principle, 45 U. Rich. L. REv. 431, 455 (2011) ("Harm, in [the Millian] sense, requires causation between the individual's action and a direct, traceable disruption to the reciprocal liberty of another to live his life with the same, sic utere-based freedom.").

190. See Ripstein, supra note 169, at 219 ("The whole point of the harm principle is to show that bad intentions and actions must be connected to bad effects to merit prohibition.").

191. Gardner, supra note 169, at 2. Moreover, Mill's own words sound in the register of personal responsibility. He explains that living in society requires certain kinds of conduct and "[t]his conduct consists, first, in not injuring the interests of one another; or rather certain interests, which, either by express legal provision or by tacit understanding, ought to be considered as rights; and secondly, in each person's bearing his share (to be fixed on some equitable principle) of the labours and sacrifices incurred for defending the society or its members from injury and molestation." MiLL, supra note 163, at 72.

192. Holtug, supra note 165, at 366 (emphasis in original). 
[T] he principle requires liberty of tastes and pursuits; of framing the plan of our life to suit our own character; of doing as we like, subject to such consequences as may follow: without impediment from our fellow-creatures, so long as what we do does not harm them, even though they should think our conduct foolish, perverse, or wrong. ${ }^{193}$

Pursuant to the harm principle, as much as we may irritate, aggravate, or offend our fellow citizens, our actions are not grounds for legal intervention absent some other kind of tangible negative impact. Therefore, the harm principle does not apply to what Mill calls "contingent" or "constructive" injuries. ${ }^{194} \mathrm{He}$ explains that to prompt legal authority there must be "a definite damage, or a definite risk of damage." 195 To trigger the harm principle, the act must result in a welfare reduction of nontrivial severity. To put it in legal terms, there must be an actual, cognizable harm. ${ }^{196}$

We have already canvassed the role of action, third parties, welfare reduction, and causation. While the other four criteria restrict when the harm principle applies, severity does the most work to limit the potentially endless scope of what constitutes harm. Thus, it is only welfare reductions of a certain nature and severity that rise to the level of harm for purposes of the harm principle. ${ }^{197}$ Failing to account for the seriousness of the harm as a necessary condition for state intervention could lead to overregulation, as even small-scale reductions in welfare could provide the foundation for state restrictions on liberty. ${ }^{198}$ Severe harms are most often understood as having a measurable negative effect on a person's basic wants and needs. ${ }^{199}$ Mill frames the issue of severity in terms of rights, explaining that living in a just society requires "not injuring the interest of one another; or rather certain interests, which, either by express legal provision or by tacit understanding, ought to be considered as rights. ${ }^{200}$ While Mill uses rights as a baseline for assessing severity, he does not articulate which rights he means, leaving the question of which harms are serious enough to warrant legal intervention up for interpretation. ${ }^{201}$ What constitutes a harm

193. MiLL, supra note 163, at 15.

194. Id. at 79 .

195. Id. at 78-79.

196. Kochan, supra note 189 , at 455.

197. See Holtug, supra note 165, at 374 (stating that "[n]ot all reductions in welfare . . amount to harms").

198. See Joel Feinberg, Harm to Others 12 (1984).

199. Holtug comments on Feinberg's idea "that an event harms a person only if it sets back her interests." See Holtug, supra note 165, at 373.

200. MiLL, supra note 163, at 72.

201. For example, Nils Holtug proposes that because Mill was committed to utilitarianism, "roughly speaking, these rights are selected on the basis of their overall tendency to promote utility if accepted ...." Holtug, supra note 165, at 381 . However, utility is not the only reason Holtug proposes that the violation of certain rights might be grounds for invoking the harm principle. He also mentions autonomy. $I d$. at 382 ("[I]t may be argued that, since it is valuable for a person to live his life according to his own plans and values, other people, or the state, should not interfere with his life against his will, at least as long as he does not interfere with other people's lives." (emphasis in original)). In fact, John Lawrence Hill has asserted that the subjective nature of what constitutes an actionable harm "has led some to contend that the 
sufficient to invoke the authority of the harm principle is a matter of great legal and philosophical debate and not an issue this Article seeks to resolve. ${ }^{202}$

\section{B. Current Antidiscrimination Harms}

Although the harm principle is most readily associated with criminal law, ${ }^{203}$ tort law, ${ }^{204}$ and more recently constitutional law, ${ }^{205}$ antidiscrimination legislation can also protect people from outside harm. ${ }^{206}$ Antidiscrimination statutes prohibit a particular kind of harmful conduct- "discrimination"-and, when that conduct occurs, provide restitution to the affected party. Current employment discrimination protections can be understood in terms of the harm principle.$^{207}$ While not all scholars agree on this point, ${ }^{208}$ a fundamental premise of this Article is that employment

concept of harm is normatively circular and always potentially contestable.” John Lawrence Hill, The Constitutional Status of Morals Legislation, 98 Ky. L.J. 1, 17 (2010).

202. See Harcourt, supra note 166, at 114 ("[Today] we focus on the types of harm, the amounts of harms, and the balance of harms. As to these questions, the harm principle offers no guidance."); see also Gardner, supra note 169, at 1 (describing the process of discerning the limits of harm for the purposes of the harm principle as "laborious and eventually frustrating").

203. See, e.g., Nina PeršaK, Criminalising Harmful Conduct: The Harm Principle, ITS LIMITS AND CONTINENTAL COUNTERPARTS (2007).

204. See generally Epstein, supra note 169 (describing the relationship between the harm principle and common law torts).

205. See, e.g., Miranda Oshige McGowan, From Outlaws to Ingroup: Romer, Lawrence, and the Inevitable Normativity of Group Recognition, 88 MINN. L. REV. 1312 (2004); J. Kelly Strader, Lawrence's Criminal Law, 16 BeRKELEY J. CRIM. L. 41 (2011); Mark Strasser, Lawrence, Mill, and Same-Sex Relationships: On Values, Valuing, and the Constitution, 15 S. CAL. INTERDISC. L.J. 285 (2006).

206. See, e.g., Eyal Zamir \& Barak Medina, Law, Economics, \& Morality 225-55 (2010); Gardner, supra note 169; see also TIMO MAKKONEN, EQUAL IN LAW, UNEQUAL IN Fact: Racial and Ethnic Discrimination and the Legal Response Thereto in Europe 251 (2012) (stating that antidiscrimination law implicates the harm principle).

207. The harm principle is not the sole foundational principle within antidiscrimination law. See, e.g., Gardner, supra note 169, at 2-3 (describing the legitimacy of antidiscrimination laws as a blend of harm principle and distributive justice rationales). However, some recent decisions have analyzed antidiscrimination claims as employment torts. See, e.g., Univ. of Texas Sw. Med. Ctr. v. Nassar, 133 S. Ct. 2517 (2013); Staub v. Proctor, 526 U.S. 411 (2011). But it is nonetheless an important one and the basis for legal intervention most relevant to this Article.

208. See e.g., Epstein, supra note 169, at 374 ("Modern concerns with discrimination, victimization, marginalization, imperfect information, and subordination are not even remote spectres in Mill's moral or descriptive universe."); id. at 410 ("But Mill would not have regarded as actionable the decision not to hire, regardless of its motive, because of his implicit devotion to the principle of freedom of association and contract, a freedom that the antidiscrimination laws necessarily abridge. But no matter what he thought, today an invidious decision not to hire someone is treated as though it were a common law tort-assault comes most quickly to mind.”); see also ZAMIR \& MEDINA, supra note 206, at 226. While antidiscrimination laws have prevailed in light of these scathing critiques, such challenges have had an impact. See id. 
discrimination is in fact harmful and, therefore, warrants a proper exercise of government power.

As discussed at length, the harm principle holds that the law should intervene when an action could generate a nonnegligible negative impact on a third party. In the context of employment discrimination, such a situation occurs when an employer makes an employment-related decision that disadvantages an employee on the basis of her protected status. ${ }^{209}$ Mill created the harm principle to assess when restrictions on personal liberty are valid uses of power. The tension within employment discrimination legislation lies between the liberty of the employer to run her business according to her own preferences and the harms employees face as potential victims of discrimination. ${ }^{210}$ Returning to the five component elements of the harm principle demonstrates why prohibiting employment discrimination warrants legal regulation as a general matter and explains why the adverse employment action functions as the archetypal legally actionable antidiscrimination harm.

1. Act

As noted, the harm principle expresses a preference for-although not an absolute requirement of - direct action. When an employer makes an employment-related decision on the basis of a protected status, she engages in an act of discrimination. ${ }^{211}$ Notably, some employment discrimination statutes also allow for plaintiffs to recover in cases of unintentional or systematic discrimination. ${ }^{212}$ As Mill himself notes, the harm principle does not necessarily exclude prohibitions on harmful conduct that result from carelessness, neglect, or happenstance, if the results are sufficiently severe. ${ }^{213}$ While the presence of a specific discriminatory act is frequently absent in disparate impact and pattern and a practice cases, employers have still actively adopted policies or screens that ultimately disadvantage individuals with the protected status.

While it may not capture all possible employment discrimination harms, the adverse employment action has clear appeal when framed in terms of the harm principle. To start, what constitutes the harmful act is frequently specific, clearly identifiable conduct. Courts have held that adverse employment actions fall into roughly three categories: (1) financial harms like getting fired or losing pay or benefits, (2) transfers or changes in responsibilities that reduce one's skills or future prospects, and (3) changes in job conditions that make continuing to work unbearable. ${ }^{214}$ All three varieties include overt acts on the part of the employer. An

209. ZAMIR \& MEDINA, supra note 206, at 241.

210. Id. at 226 .

211. See Gardner, supra note 169, at 4 ("Someone discriminates directly, for instance, if he treats a woman 'less favourably' than he would a man 'on grounds of her sex'. The definitional elements of this activity approximate in a number of ways to the definitional elements of a conventional harm-based tort." (citation omitted)).

212. See, e.g., supra notes 24-28 and accompanying text (discussing the disparate impact doctrine).

213. See MiLl, supra note 163 , at 72.

214. See Barton v. Zimmer, Inc., 662 F.3d 448, 453-54 (7th Cir. 2011) (holding that adverse employment actions "generally fall into three categories: (1) termination or reduction 
employer must actively decide to fire or transfer an individual. The third type, which includes hostile work environment claims (described at length Part IV), is the most amorphous because what amounts to unbearable conditions may not be an isolated event but the cumulative effect of offensive conduct and smaller slights over time. ${ }^{215}$ Whereas the harmful conduct in disparate impact claims can be murky because those harms are unintentional or accrue over time, many adverse employment actions occur as single, identifiable discriminatory events. Hence, the clear-cut nature of the adverse employment action makes it easier for courts to discern with relative certainty than more complex forms of exclusion, like structural barriers, and by consequence easier for courts to address and remedy.

\section{Third Party}

The harm principle also requires that the harm be toward a third party. In the case of employment discrimination, this element is probably most clear. The employer (the discriminator) acts in a way that negatively impacts the employee or applicant (the object of discrimination). Thus, the harm at stake is quite obviously experienced by a third party.

Again, the application of this harm principle criterion to the adverse employment action is extremely straightforward. Even the phrase "disparate treatment" indicates the clear presence of a third-party harm. There must be an explicit object of discrimination, an individual who has been treated disparately. Moreover, the very verbs that make up adverse employment actions require a direct object. An employer must fire or transfer someone. Thus, the adverse employment action is again appealing as a type of antidiscrimination harm because there must often be a definitive third party.

\section{Welfare Reduction}

The next defining characteristic of the harm principle is welfare reduction. Welfare reduction can, of course, take the form of an increase in negative welfare or a decrease in positive welfare. Let us now consider what makes employment discrimination harmful. Paul Brest offers some guidance on this issue in his path-breaking essay In Defense of the Antidiscrimination Principle. ${ }^{216}$ In describing the harms of discrimination, Brest writes:

Often, the most obvious harm is the denial of the opportunity to secure a desired benefit - a job, a night's lodging at a motel, a vote. But this does not completely describe the consequences of race-dependent decisionmaking. Decisions based on assumptions of intrinsic worth and

in compensation, fringe benefits, or other financial terms of employment; (2) transfers or changes in job duties that cause an employee's skills to atrophy and reduce future career prospects; and (3) unbearable changes in job conditions, such as a hostile work environment or conditions amounting to constructive discharge").

215. See infra Part IV.B.1.

216. See Gardner, supra note 169, at 6 (discussing Brest's antidiscrimination principle as informative regarding the harm of employment discrimination). 
selective indifference inflict psychological injury by stigmatizing their victims as inferior. Moreover, because acts of discrimination tend to occur in pervasive patterns, their victims suffer especially frustrating, cumulative and debilitating injuries. ${ }^{217}$

Brest identifies three kinds of potential antidiscrimination harms: (1) benefit denial, (2) stigmatic harm, and (3) systematic disadvantage. This Article acknowledges the existence of other kinds of antidiscrimination harms but focuses on the first: denial of an opportunity to secure a desired benefit, a classic example of a reduction in positive welfare.

While the psychological discomfort that results from being associated with negative stereotypes and stigma was discussed in great detail in the previous Part, this Article focuses on the effect of that psychological discomfort on an employee's ability to obtain an employment-related benefit, not on the psychological discomfort itself. According to a Millian analysis, we do not restrict an employer's ability to differentiate on the basis of protected statuses simply because we find that differentiation offensive or morally reprehensible, although it may very well be. We restrict an employer's ability to differentiate on the basis of protected statuses because it is harmful.

Applying the concept of welfare reduction to adverse employment actions is tautological. Adverse employment actions reduce welfare because they are adverse. Statutes define them as creating disadvantage for the affected individuals. Again, the adverse employment action meets the rigors of the harm principle with ease. They are by their very definition harmful.

\section{Causation}

Turning now to causation, the discriminatory act or policy must lead to the denial of an employment-related benefit. Antidiscrimination law can be understood as mirroring tort law "by requiring a nexus of wrongdoing between the complainant and the defendant." ${ }^{218}$ If the act or policy does not deny a benefit or if the benefit denial is the result of some unrelated impetus, the employee will not be able to allege discrimination. Employment discrimination legislation therefore targets specific types of employment-related harms experienced by individual employees as the result of the employer's conduct. ${ }^{219}$

Adverse employment actions as antidiscrimination harms have appeal with respect to causation as well. Because they tend to be direct acts, drawing the causal nexus is likewise straightforward. Unlike disparate impact claims, or even hostile work environment claims, which can be more attenuated, the employee's welfare reduction is clear in cases of disparate treatment. The employer's decision to not

217. Paul Brest, Foreward, In Defense of the Antidiscrimination Principle, 90 HARV. L. REV. 1, 8 (1976).

218. Gardner, supra note 169 , at 4 .

219. Hill, supra note 201, at 50 ("[A]nti-discrimination laws prohibit discrimination in particular cases and, to that extent, prevent particularized harms to specific individuals."). Of course, beyond merely preventing harm, antidiscrimination laws also have the effect of promoting the equality as a normative value. 
promote the individual is what is responsible for the employee's lack of access to additional pay or other job benefits.

\section{Severity}

Now moving to the final component of the harm principle analysis: severity. In criticizing the invocation of the harm principle in the context of employment discrimination law, Richard Epstein opines:

[I]f one were to say that the failure to hire on account of race, sex, or age is actionable, then why is not any refusal to make an offer actionable, regardless of its motivation: the harm is present in all cases, and it may impose a greater hurt to reject someone because his work is amateurish than because he is black or white. ${ }^{220}$

Epstein is right. It would seem that the amateurish worker experiences exactly the same welfare reduction as the individual facing discrimination: the employer takes an action against an employee that denies the employee access to a desired benefit. The first four harm principle criteria are identical here.

As mentioned, severity is the primary mechanism by which to differentiate between the kinds of harms that warrant legal regulation and the kinds that don't. The question arises, why is it appropriate to limit the employer's liberty in the case of the candidate of color but not in the case of an amateurish candidate? The answer is because the harm experienced by the candidate of color is worse. It differs not in kind but in degree.

Remember that Mill describes severe harms as those that infringe on interests that "either by express legal provision or by tacit understanding, ought to be considered as rights." ${ }^{.21}$ Individuals have certain rights, both in terms of their freedom of contract and their ability to access certain social goods, and those rights have been historically and systematically denied on the basis of now protected statuses such as race, sex, religion, age, and disability, leading to widespread disadvantage on those bases. ${ }^{222}$ While there is no explicit legal "right to work," there are strong norms in favor of fair employment. ${ }^{223}$ No individual is entitled to any particular job, yet she is arguably entitled to being evaluated on the basis of her skills and abilities. The very fact that individuals have historically experienced widespread, systematic disadvantage on the basis of race is enough to determine that the harm experienced by the candidate of color is actually greater. ${ }^{224}$ Again, the relevant difference is not the nature - but rather the severity - of the harm.

Not surprisingly then, severity is likewise the only place where the adverse employment action also falters. How adverse does an action have to be before courts

220. Epstein, supra note 169, at 411.

221. MiLl, supra 163, at 72.

222. See ZAMIR \& Medina, supra note 206, at 236.

223. See Philip Harvey, Human Rights and Economic Policy Discourse: Taking Economic and Social Rights Seriously, 33 Colum. HuM. RTS. L. REV. 363, 383-86 (2002) (discussing the absence of an explicit right to work in the United States).

224. See ZAMIR \& MEDINA, supra note 206, at 236. 
will consider it legally actionable? Different circuits have arrived at different answers. The First, Seventh, Ninth, Tenth, Eleventh, and D.C. Circuits take an expansive view of the adverse employment action, including denials of opportunities and shifts in benefits or compensation. ${ }^{225}$ The Second, Third, and Sixth Circuits have adopted an intermediate test, asking whether the adverse action in question materially affects the individual's terms and conditions of employment. ${ }^{226}$ Finally, the Fifth and Eighth Circuits have the most restrictive definition, limiting what constitutes a legally actionable adverse employment action to "ultimate actions" like hiring and firing. ${ }^{227}$ Hence while the adverse employment action may be among the clearest, most straightforward application of the harm principle to employment discrimination, it is not without its ambiguities.

\section{Stereotype Threat Triggers as Harmful}

In many instances, adverse employment actions are clearly harmful in the Millian sense. Yet, as discussed in Part II, numerous studies have documented the very real impact of stereotype threat on the performance of individuals who face stigma. In a very simple sense, stereotype threat is harmful because it can measurably depress ability. However, as discussed, not all harms fall within the purview of the harm principle. Such an application would cause the harm principle to collapse under its own weight, raising the following question: given that stereotype threat negatively impacts job performance and opportunity, should conduct that activates stereotype threat constitute a legally recognized type of employment discrimination harm? To answer this question, we can look again to the harm principle. To be valid grounds for legal regulation pursuant to the harm principle, the targeted action must fulfill the five criteria for harmful conduct.

\section{Act}

Acts, as opposed to omissions, tend to be considered harmful pursuant to the harm principle. A wide range of conduct or work conditions could activate stereotype threat. For example, mentioning or inquiring about an individual's protected status could trigger stereotype threat. That conduct quite clearly constitutes action. Inaction, such as the failure to hire a diverse, vertically integrated group of employees, could also activate stereotype threat if the employee feels tokenized. While the outcomes could be the same, lowered performance and reduced job investment, one may be a more appropriate application of the harm principle than the other. Prohibiting references to protected status would be relatively straightforward. By contrast, it is far more challenging to regulate the failure to do something, especially if there is no one policy or person that leads to the exclusion. With respect to tokenism, several factors affect hiring with any number of individuals in charge

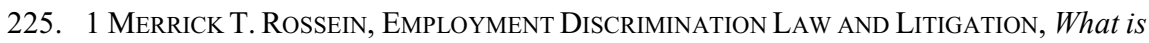
an adverse employment action, $\S 2: 4.75$ (2015).

226. $I d$.

227. Id. 
of making those various decisions. Because it is not clear who bears the responsibility for the underrepresentation, it is also not clear how to effectively prohibit it.

Furthermore, the harm principle only restricts conduct that could negatively impact another individual. Applying the harm principle to circumstances in which inaction generates the welfare reduction would shift the principle from one that restricts liberty by prohibiting certain conduct to a principle that restricts liberty by requiring certain conduct. The desirability of such requirements aside - to be sure a more diverse labor force is an appealing proposition - such an application would be outside the parameters of the harm principle, as it is understood here. This Article is not advocating the regulation of all stereotype threat-related harms in the workplace but rather a subset of those harms that are easy to regulate. Hence, some stereotype threat triggers may lend themselves to being construed as employment discrimination harms, while others may not.

\section{Third Party}

Another requirement of the harm principle is that the negative impact happens to a third party. The presence of a third party ensures that the power of regulation cannot be invoked for purely paternalistic endeavors. Significantly, almost all of our actions, even those that at first appear self-regarding, may impact others. ${ }^{228}$ While this issue is relevant for the legitimacy of arguably paternalistic public health ${ }^{229}$ or morals legislation ${ }^{230}$ enacted under the harm principle, it is of less importance here. That is because stereotype threat primarily harms the employee or applicant.

\section{Welfare Reduction}

The third criterion, welfare reduction, requires more analysis. Mill himself was quite clear that noxious conduct that does not negatively impact others falls outside of the scope of the harm principle. ${ }^{231}$ That is to say, one cannot claim conduct is harmful merely because she finds it distasteful but experiences no other form of welfare reduction. As mentioned, the law should not intervene because some find the challenged conduct to be, in Mill's words, "foolish, perverse, or wrong." ${ }^{232}$ To warrant legal intervention, the conduct must lead to tangible harm. Although they may initially seem purely psychological, the kinds of harms caused by stereotype threat are both direct and measurable.

That said, there are clearly certain psychological harms at play. Even in the case of traditional kinds of employment discrimination (i.e., adverse employment actions), the objects of the discrimination may experience a psychic harm in addition to the denial of the desired benefit. ${ }^{233}$ Moreover, certain classes of

228. See supra note 172 and accompanying text.

229. See, e.g., Thaddeus Mason Pope, Balancing Public Health Against Individual Liberty: The Ethics of Smoking Regulations, 61 U. PITT. L. REV. 419 (2000).

230. See supra note 205.

231. See supra notes 182-183, notes 228-230 and accompanying text.

232. MiLL, supra note 163 , at 15.

233. While potentially a consequence of legally actionable employment discrimination, psychological harm is not a requirement of it. See ZAMIR \& MEDINA, supra note 206, at 236. 
stereotype threat triggers, such as the simple act of asking an unwanted question, could be construed as harmful. Privacy scholar Daniel Solove identifies this privacy-associated harm as "interrogation." 234 Interrogation occurs when a person or an entity simply asks a question or makes an inquiry that implicates private information. ${ }^{235}$ An unwanted, probing question may deprive an individual of her autonomy by compelling her-however gently - to respond against her will, thereby psychologically harming her. ${ }^{236}$ Additionally, stereotype threat itself brings unpleasant feelings. The state of psychological arousal associated with the fear of confirming a stereotype is a necessary element, making a negative effect endemic to the very nature of stereotype threat. ${ }^{237}$ While these psychological harms are very real, they are not the focus here.

Activating stereotype threat is not harmful merely because it could be offensive but rather because it generates actual, tangible harm to an employee's job performance, which in turn leads to the denial of an employment-related benefit. Remember that to warrant legal intervention, Mill himself explains that the targeted conduct must generate "a definite damage, or a definite risk of damage." ${ }^{238}$ Triggering stereotype threat reduces welfare by impeding an employee's ability to perform to her actual potential and by enabling the associated detriment to her work life. The harm of stereotype threat is the decreased ability and negative job consequences that inevitably follow the prerequisite psychological discomfort. To be sure, the psychological harm associated with stereotype threat may seem to fall into the class of dignitary harms Mill places outside the scope of the harm principle. Yet, it is not the psychic harm itself but its effect. While activating stereotype threat may not cause its own independent "definite damage," it creates "a definite risk of damage." ${ }^{239}$ Because activating stereotype threat could culminate in the same welfare reductions associated with adverse employment actions, that conduct is equally harmful.

\section{Causation}

Additionally, the harm principle requires causation. That is, the harm must be the result of the conduct. Again this serves as a limiting mechanism to bypass overregulation. As Mill himself acknowledged, the notion of an indirect harm could be expanded without limit. ${ }^{240}$ However, stereotype threat is the consequence of the employer's action. (Of course this issue again raises the action/inaction point described above, tipping in favor of covering the stereotype threat triggers that involve positive conduct and, by consequence, are simpler to regulate.) Recall that

234. Daniel J. Solove, A Taxonomy of Privacy, 154 U. PA. L. REV. 477, 499-504 (2006) (discussing the harm of interrogation).

235. Id.

236. Id. at 500 (explaining the harm of interrogation).

237. See, e.g., Roberson \& Kulik, supra note 71, at 26 (defining stereotype threat as "the psychological experience of a person who, while engaged in a task, is aware of a stereotype about his or her identity group suggesting that he or she will not perform well on that task").

238. MiLL, supra note 163, at 78-79 (emphasis added).

239. Id.

240. Id. 
stereotype threat requires a stereotype-relevant evaluation in an identity-dependent domain, as well as a trigger. ${ }^{241}$ These factors combine to create the negative arousal associated with stereotype threat. A wide variety of conduct could activate stereotype threat in the identity-dependent domain of employment, such as asking an employee about protected status, referencing her protected status, and exposing her to stereotypical materials. While these actions on their own may not be sufficient to independently create stereotype threat, such triggers are nonetheless necessary. The harms associated with stereotype threat are the results of that conduct. Put another way, stereotype threat triggers are but-for causes of the resulting stereotype threat.

Some scholars might assert that stereotype threat is an indirect antidiscrimination harm and perhaps then not the rightful subject of legal regulation under the harm principle. ${ }^{242}$ Epstein explains that once antidiscrimination norms move into the realm of preference regulation, we should be wary of invoking law to enforce them:

[S]ome indirect harms of discrimination exist, and in many social settings they matter. Yet in this context it is useful to rely on informal and reputational sanctions that may be brought to bear against persons who deviate from the dominant social norms. These sanctions offer a powerful check against the outlandish forms of discrimination. ${ }^{243}$

Epstein might advocate the use of social sanctions for the kinds of unintentional harms caused by stereotype threat and, to some extent, such prohibitions are already in place. For example, employers are advised not to ask about protected status during hiring because those questions could be used as evidence of discrimination if an adverse employment action occurs down the line. ${ }^{244}$ However, failing to

241. See supra Part II.A.

242. See, e.g., Epstein, supra note 169.

243. Id. at 413.

244. See, e.g., 2 Fair Employment Practices $\S 16: 2$ (2014) (advising employers not to ask about a variety of traits and statuses absent "a proven relationship to the job being sought," including "medical or mental health history," "national origin and citizenship status," "marital status," and "age”); Guide to HR Policies And Procedures Manuals Appx § 2:11 (2014) (providing examples of acceptable and unacceptable inquiries related to age, sex, race, national origin, and disability); 1 Policies AND PRACTICES $\S 38: 6$ (2013) (explaining that "[a]n interviewer's discriminatory comments during an interview may suggest pretext for discrimination - even if someone else has final hiring authority"); see also Mark A. Rothstein, Genetic Secrets: A Policy Framework, in Genetic Secrets: Protecting Privacy \& CONFidentiality in THE Genetic ERA 459-60 (Mark A. Rothstein ed., 1997) (“Technically, it is lawful for an employer to ask an applicant to reveal information such as race or sex, although hardly any employers do so because there are few circumstances under which such information can be used lawfully."); William R. Corbett, What Is in GINA's Genes? The Curious Case of the Mutant-Hybrid Employment Law, 64 OKLA. L. REV. 1, 3 (2011) ("In cases in which the protected characteristic is not obvious, an employer may be well advised not to ask about it, but that is because such an inquiry may help the employee prove that an adverse employment action was taken because of the protected characteristic - not because the statute protects the privacy of the information."). 
acknowledge activating stereotype threat as an independent employment discrimination harm ignores the intrinsic harm of the stereotype threat itself. ${ }^{245}$

Moreover, the relative directness of any harm is always up for interpretation. As John Lawrence Hill opines, once a harm warrants regulation, there is not a clear boundary delineating which such harms require public regulation and which harms are better suited to the kind of private regulation espoused by Epstein:

[T] here is no purely objective concept of harm to which we can appeal to tell us where to draw the line between the private and the public realms. In order to draw this normative and legal line, we must already have a background set of normative considerations that guide our understanding of what it means for something to be "harm."246

Given the existing federal statutes specifically designed to avoid discrimination on the basis of race, sex, age, disability, and genetic information in the workplace, preexisting normative and legal values tip in favor of regulation.

\section{Severity}

The fifth and final criterion of the harm principle is severity, ensuring that entities do not overregulate by passing laws and policies in response to trivial injuries. It is not enough to have one's interests be negatively affected. Rather, those interests must be adversely impacted in a way that implicates a person's legitimate moral or legal interests. ${ }^{247}$ As stated, existing laws and norms indicate that antidiscrimination harms - particularly the deprivation of employment benefits on the basis of race, sex, age, disability, or genetic information-are sufficient basis for a legal action. Acknowledging the harms associated with stereotype threat is thereby a logical extension of the current antidiscrimination regime. However, one could lodge several objections to this proposal.

One response could be that, while creating the potential for harm, the same conduct may not actually harm all the individuals affected. That is to say, different people experience stereotype threat to different degrees. Whereas an inquiry into one person's race might have a detrimental effect, a similar inquiry into another person's race may have a neutral — or even a beneficial — effect on job performance. This observation is empirically true and thus a fair critique. ${ }^{248}$ The same stereotype threat triggers will not harm everyone and, even of the individuals these triggers do harm, they may not harm those individuals in equal ways. ${ }^{249}$ Ideally, we could cull

245. See infra Part IV.A. (making the full argument for expanding employment discrimination harms to include the harms associated with stereotype threat).

246. Hill, supra note 201, at 17.

247. Id. (" $[\mathrm{T}] \mathrm{o}$ be harmed, one must be injured or have one's interests adversely affected (the objective aspect) in a way that violates one's legitimate moral or legal claims (the normative aspect).").

248. See supra note 13 .

249. See Block et al, supra note 12, at 586 ("We believe that individuals' responses to stereotype threat will be influenced by both individual factors, such as level of group identification and career stage, as well as organizational factors that provide cues about the 
the most truly harmful conduct from the benign so as to avoid unduly restricting employer behavior. But, the law is a notoriously blunt and imperfect instrument. Take, for example, the crime of harmless trespass. Arthur Ripstein describes a scenario in which someone sneaks into another person's home without her permission, using tools that do not break the lock, to nap in her bed. ${ }^{250} \mathrm{He}$ wears hypoallergenic, lint-free pajamas and a hairnet, and he even brings his own sheets and pillowcase. ${ }^{251}$ His actions confer no harm, yet they are nevertheless illegal. Proponents of the harm principle would assert that criminalizing the napper's trespass seeks to protect the community against the other harmful varieties. ${ }^{252}$ That the rule against trespass also captures harmless conduct is purely happenstance. The harm principle can, therefore, suffer from an overbreadth problem: it may outlaw some conduct that produces no harm in and of itself to outlaw the conduct that does. But that is the best the law can do at times.

Actions that activate stereotype threat, like sleeping in a stranger's bed, are typically not social goods so valuable that they are vulnerable to the argument that prohibiting them throws out the baby with the bathwater. ${ }^{253}$ The criticism that all stereotype threat triggers are not equally harmful, while valid, speaks more strongly to the crudeness of the harm principle as a basis for legal regulation as a general matter, rather than its invocation here. In fact, prohibiting certain seemingly innocuous actions that disproportionately affect members of a protected group is the very foundation of disparate impact doctrine and hence a core value of American antidiscrimination law. ${ }^{254} \mathrm{An}$ act or policy need not harm all individuals who share a protected status in equal measure for it to be considered unfairly discriminatory.

Finally, critics may assert that expanding employment discrimination harms to stereotype threat is outside the scope of the Millian harm principle. While this Article acknowledges that my reading of the harm principle may exceed the kinds of wrongs initially envisioned by Mill in 1859, it accepts the expansion of the harm principle in the past 150 years as an integral aspect of the evolution of modern American statutory and common law. Whereas this Article takes no position on the rightness or wrongness of this expansion, others have challenged both the wisdom and validity of twentieth and twenty-first century invocations of Mill's now famous proposition. 255

salience of group membership, such as the demographic composition and cultural centeredness of the workplace. An important avenue for future research is to understand the factors that influence which response an individual will have to stereotype threat.").

250. Ripstein, supra note 169 , at 218-22.

251. Id.

252. Id. at 222-29.

253. Because so many actions can have unintended negative consequences, applying the harm principle must involve some cost-benefit analysis. As Epstein, supra note 169, points out, the basic functioning of the market could be construed as harmful because when one person wins in the market, her competitors inevitably lose. Part IV.C explores the situations in which stereotype threat triggers could be welfare-enhancing.

254. See Barry Goldstein \& Patrick O. Patterson, Ricci v. de Stefano: Does It Herald an 'Evil Day, ' or Does It Lack Staying Power?, 40 U. MEM. L. ReV. 705, 753-65 (2010).

255. See, e.g., Epstein, supra note 169, at 399 ("The modern expansion of the harm principle . . . is destructive of the original Millian mission to use the harm principle as a way 
Whether stereotype threat triggers are harmful depends upon how the purpose of the harm principle is defined, either as protection of liberty or as freedom from harm. If the function of the harm principle is to prevent governments from restricting personal liberty, preventing employers from referencing protected status could quite clearly undermine that goal. Conversely, if the purpose of the harm principle is to justify regulations that protect individuals from outside harm, applying the harm principle to stereotype threat certainly serves that objective.

Harms from stereotype threat matter because the very nature of discrimination has changed. While the laws outlined in Part I were effective tools to combat the kind of outright exclusion and differential treatment that characterized employment discrimination in the second half of the twentieth century, present-day discrimination operates on a far more subtle scale, relying on existing structural, institutional, and attitudinal barriers to perpetuate existing social and economic disparities. Stereotype threat is precisely the kind of nuanced process that contributes to this type of second-generation discrimination.

Harm prevention is often invoked as a basis for law. ${ }^{256}$ While scholars, legal philosophers, and lawmakers may disagree about the meaning of harm and, hence, the appropriate scope of legal regulation, the harm principle has nonetheless endured for a century and a half. With respect to employment discrimination, the law prohibits employers from engaging in conduct that either directly - or indirectly-causes a tangible harm to applicants or employees on the basis of a protected trait. However, stereotype threat triggers are also harmful in the Millian sense. When a negative stereotype is in play, drawing attention to an individual's protected status can cause her great psychological discomfort and distress, sufficient to affect her performance at work. This negative impact is not merely a psychic cost, it also bears itself out as a real disadvantage in the workplace. It is not enough to merely outlaw adverse employment actions: to fully protect employees from discrimination, the law must likewise acknowledge the effect of these subtle, cumulative harms.

\section{TOWARD EXPANDED EMPLOYMENT DISCRIMINATION HARMS}

If truly creating a fair and equitable workplace is the goal of employment discrimination law, targeting subtle and unobvious causes of inequity, such as stereotype threat, is the next logical step. It is not enough to challenge intent, as proposed by the implicit bias literature. ${ }^{257}$ The law must also expand its notion of what constitutes an employment discrimination harm beyond the adverse employment action. This Part begins with the need to rethink the notion of harm in the workplace. It then notes some existing departures from the adverse employment

to restrain the scope of government action."); see also Harcourt, supra note 166, at 113 ("The harm principle is effectively collapsing under the weight of its own success. Claims of harm have become so pervasive that the harm principle has become meaningless: the harm principle no longer serves the function of a critical principle because non-trivial harm arguments permeate the debate." (emphasis in original)). As this Article advocates extending the existing antidiscrimination regime, it quite clearly does not employ the harm principle as a means to restrain government action.

256. See supra Part III.A.

257. See, e.g., Jolls \& Sunstein, supra note 56; Krieger, supra note 7. 
action that indicate a willingness to think more expansively about harmful conduct. Next, the Article acknowledges that, at times, stereotype threat triggers could actually further antidiscrimination aims and are, therefore, not harmful. Finally, Part IV ends by exploring the various ways the law could intervene to protect against the harms of stereotype threat.

\section{A. Why Expand Employment Discrimination Harms}

While stereotype threat can produce real harm in the workplace, federal employment discrimination law fails to protect employees against this particular employment discrimination harm. ${ }^{258}$ Admittedly, recognizing stereotype threat triggers as harmful cuts against certain well-known employment discrimination precedents. For example, the Supreme Court famously held that Title VII is not "a general civility code." 259 In other words, antidiscrimination law does not require employers and employees to be nice to each other. ${ }^{260}$ Employment discrimination statutes are not designed to address hurt feelings. Further, courts have also been skeptical of so-called "stray remarks," potentially discriminatory comments made by non-decision makers or outside the context of job-related decisions. ${ }^{261}$ This Article openly challenges the existing consensus that such workplace interactions are not harmful from an antidiscrimination perspective. The literature on stereotype threat reveals that seemingly innocuous or "one-off" conduct can lead to disparities on the basis of legally protected antidiscrimination categories.

Regardless of the existing doctrine, we must rethink employment discrimination harms if we want to address the second-generation discrimination described in Part I. Subtle, cumulative discrimination is not the fault of a single, intentional bad actor and, as a result, often cannot be traced to a specific, isolated adverse employment action. ${ }^{262}$ In fact, stereotype threat can operate regardless of an employer's best efforts. $^{263}$ Even nondiscriminatory policies can still generate discriminatory

258. For example, many federal employment discrimination laws do not stop employers from asking about protected status. See Corbett, supra note 244, at 3 ("Title VII of the Civil Rights Act of 1964 and the Age Discrimination in Employment Act of 1967 (ADEA) do not prohibit employers from inquiring about or revealing to others an employee's color, race, sex, religion, national origin, or age."); Rothstein, supra note 244, at 459 ("Title VII of the Civil Rights Act of 1964 prohibits discrimination in employment on the basis of race, color, religion, sex, or national origin. Title VII bans using the information in a discriminatory manner rather than collecting the information.").

259. See Oncale v. Sundowner Offshore Servs. Inc., 523 U.S. 75, 81 (1998).

260. Id.

261. See, e.g., Mondero v. Salt River Project, 400 F.3d 1207 (9th Cir. 2005); Ayala-Gerena v. Bristol Myers-Squibb Co., 95 F.3d 86 (1st Cir. 1996); see also 1 RosseIn, supra note 225, at $\S 2: 16.50$. Thus, my proposal cuts against Justice Brennan's statement in Price Waterhouse v. Hopkins that "[r]emarks at work that are based on sex stereotypes do not inevitably prove that gender played a part in a particular employment decision." 490 U.S. 228, 251 (1989), superseded by statute, Civil Rights Act of 1991, Pub. L. No. 102-166, § 107(a), 105 Stat. 1075 (codified at 42 U.S.C. $\$ 2000 \mathrm{e}-2(\mathrm{~m})$ (providing that complaining party must show that the protected status was a "motivating factor")).

262. See Green, supra note 40, at 119.

263. Roberson \& Kulik, supra note 71, at 25. 
outcomes because stereotype threat reduces actual performance ${ }^{264}$ Consequently, to address the resulting disparities in employment, the focus must be-as Samuel Bagenstos puts it - "not on the individual fault of the discriminator, but on the social harm of discrimination." ${ }^{265}$ Going beyond the adverse employment action inevitably rejects the "perpetrator perspective" 266 in favor of addressing systemic disparities. But this outcome is desirable: to eradicate second-generation discrimination, we must hold employers accountable for minimizing even the unintentional presence of discriminatory forces in the workplace. ${ }^{267}$

The centrality of the adverse employment action shuts out claims for all kinds of smaller-scale negative differential treatment. Examples of harmful conduct outside the scope of the adverse employment action include any number of things, such as poor performance evaluations, undesirable lateral transfers, a change of job title, or the failure to offer training or mentoring, so long as there is not a related compensation decision. ${ }^{268}$ Thus, courts have not recognized these kinds of actions as the bases for disparate treatment claims. ${ }^{269}$ This singular focus on large-scale negative differential treatment ignores the lived reality of employment discrimination plaintiffs who report that they experience discrimination in actions both large and small. ${ }^{270}$

Obviously, a potential plaintiff could wait until her employer's conduct culminates in a significant enough employment action to be legally cognizable, but, from a practical perspective, it seems unlikely that a person would continue to invest her full efforts. ${ }^{271}$ These kinds of smaller slights are exactly the sort of conduct that triggers stereotype threat, making workers vulnerable to the kinds of coping mechanisms described in Part II. Those coping mechanisms could create a legitimate basis for adverse employment actions. If an employee withdraws from her job, her withdrawal will likely result in underperformance. That underperformance could in turn lead her to be passed over for promotion or even to be demoted or fired. But by the time the employee is withdrawn and underperforming, the resulting adverse employment action will, of course, be valid and appear completely meritocratic. ${ }^{272}$ She is no longer acting like a committed employee. Prohibiting an employer from activating stereotype threat - before it manifests as disengagement, disidentification, or withdrawal-preempts the associated lackluster performance and eliminates the chance of a subsequent adverse employment action on that basis. It also potentially

264. Id. at 37 .

265. Bagenstos, supra note 15 , at 491 .

266. The "perpetrator perspective" focuses on the fault of the particular discriminator. See Alan David Freeman, Legitimizing Racial Discrimination Through Antidiscrimination Law: A Critical Review of Supreme Court Doctrine, 62 MinN. L. REv. 1049, 1052-54 (1978).

267. See Green, supra note 40, at 143.

268. Id. at 116-17; Sperino, supra note 42 at 93, 103-04.

269. See Green, supra note 40, at 117. Consequently, as Sandra Sperino explains, minor adverse actions get improperly forced into the harassment rubric. Sperino, supra note 42, at 103-04.

270. Sperino, supra note 42 , at 85 .

271. Id. at 93 .

272. See Green, supra note 15 , at 1005 (making a similar argument in the context of racial emotion). 
saves that employer from the difficulty of defending a legal claim down the line. By consequence, casting certain stereotype threat triggers as harmful not only catches the harm at an early stage but also could cut down on future discrimination claims.

Furthermore, acknowledging stereotype threat-based harms would better reflect the lived realities of individuals who face discrimination. An employee who experiences stereotype threat may simultaneously encounter discrimination and underperform. While the law permits recovery for mixed-motive claims - claims that include both valid and discriminatory reasons for the adverse employment action — under Title VII, plaintiffs are severely restricted with respect to their available remedies. Title VII's mixed-motive provision provides "an unlawful employment practice is established when the complaining party demonstrates that race, color, religion, sex, or national origin was a motivating factor for any employment practice, even though other factors also motivated the practice." ${ }^{273}$ However, after a plaintiff establishes her claim under that provision, an employer can avoid back pay, damages, and court-ordered reinstatement if it can prove it "would have taken the same action in the absence of the impermissible motivating factor." 274 The mixed-motive doctrine therefore does little to protect employees. Further, the ADEA does not permit mixed-motive actions, ${ }^{275}$ and the status of mixed-motive claims under the ADA remains unsettled. It is unclear whether courts will interpret the statute to conform with Title VII or the ADEA. ${ }^{276}$ Once job performance diminishes in the wake of stereotype threat, plaintiffs enjoy very little meaningful legal recourse, even if they can establish discrimination occurred.

Imagine this hypothetical. A female engineer is assigned to a high-status project. In response to one of her suggestions, her supervisor says, "Of course you think that, you're a woman." She feels self-conscious and fails to make additional contributions, not participating in an equal capacity to her male colleagues. Her lack of participation leads her to be transferred to a less prestigious department but for comparable pay. The transfer further discourages her, and she begins to avoid seeking feedback and engaging with her colleagues. Eventually, the employer terminates her. Even if the engineer could establish that her employer engaged in enough sexist conduct to overcome the stray remarks doctrine and sustain a valid claim for disparate treatment (an already unlikely result), because of mixed-motive jurisprudence, a court could look to her diminished performance to justify the resulting termination, thereby avoiding paying her damages or having to reinstate her.

Although society should strive to eliminate negative stereotypes altogether (even absent explicit, first-generation discrimination), ${ }^{277}$ in the meantime we should not ignore the very real effects of existing stereotypes on objects of discrimination. ${ }^{278}$

273. 42 U.S.C. $\S 2000 \mathrm{e}-2(\mathrm{~m})(2012)$.

274. Id. $\S 2000 \mathrm{e}-5(\mathrm{~g})(2)(\mathrm{B})$.

275. See Gross v. FBL Fin. Servs., 557 U.S. 167 (2009) (applying a "because of" standard to ADEA claims).

276. Compare Lewis v. Humboldt Acquisition Corp., 681 F.3d 312 (6th Cir. 2012) (en banc) (applying Gross to ADA mixed-motive claims) with Univ. of Tex. Sw. Med. Ctr v. Nassar, 133 S.Ct. 2517 (2013) (distinguishing between status-based claims and retaliation claims with respect to mixed motive, perhaps leaving the door open for Title I mixed-motive claims).

277. See Sturm, supra note 4, at 556.

278. Roberson \& Kulik, supra note 71, at 37. 
Simply ignoring the realities of stereotype threat and second-generation discrimination because they are too complex or unsettling will do nothing to dismantle their effects. ${ }^{279}$ Because existing law falls short, this Article proposes moving beyond the adverse employment action.

\section{B. Beyond the Adverse Employment Action}

Although the adverse employment action remains the paradigmatic employment discrimination harm, it is not the sole legally actionable harm associated with discrimination on the job. This subpart explores the ways in which both courts and legislatures have expanded the notion of what constitutes an actionable wrong in the context of employment. These laws and doctrines express a willingness to think beyond the adverse employment action.

\section{Hostile Work Environment Doctrine}

As explained in Part I, Title VII prevents employers from engaging in a variety of adverse employment actions, such as failing to hire, firing, or classifying employees, on the basis of race, color, religion, sex, or national origin. Despite the statute's focus on explicit intentional discrimination, courts have interpreted Title VII to cover a broader range of employment discrimination harms in keeping with the spirit of the law. This Article has already described one of these doctrines, disparate impact. However, another judge-made canon provides an even more useful basis for expanding employment discrimination harms: plaintiffs may sue for hostile work environments.

In claims for hostile work environment, litigants do not have to demonstrate that they experienced an adverse employment action ${ }^{280}$ but rather that the relevant conduct "has the purpose or effect of unreasonably interfering with an individual's work performance or creating an intimidating, hostile, or offensive working environment." ${ }^{281}$ While the regulation quoted here pertains to sexual harassment, the EEOC has taken the position that those same principles apply equally to harassment on the basis of race or color. ${ }^{282}$ To prevail in a case of hostile work environment for sexual harassment, plaintiffs must generally show that (1) the conduct was so severe or pervasive as to alter the terms and conditions of employment, (2) the conduct was offensive to the individual plaintiff, and (3) the conduct would have likewise been offensive to a reasonable person. ${ }^{283}$ With respect to hostile work environments based on race or color, courts have required plaintiffs to demonstrate that (1) unwelcome harassment occurred, (2) the harassment was based on protected status, and (3) the harassment altered a condition of

279. See Green, supra note 40, at 151 (making a similar point with respect to structural discrimination).

280. Green, supra note 15, at 994 (noting the absence of the need for "an identifiable, discrete adverse employment action" in hostile work environment claims).

281. 29 C.F.R. § 1604.11(a)(3) (2015) (EEOC guidelines for sexual harassment).

282. Id. § 1604.11(a)(3), n.1.

283. 3 LeX K. LARSOn, EMPloyment Discrimination $\S 46.05$ (2d ed. 2015). 
employment. ${ }^{284}$ Claims for hostile work environment demonstrate that an outright adverse employment action, such as firing or failing to promote, are at times unnecessary for establishing valid claims for employment discrimination. Instead, it may be enough for an employee to show that her employer's conduct had a deleterious effect on her ability to perform her job.

Pursuant to Title VII, sexual harassment plaintiffs may be entitled to compensatory and punitive damages, as well as injunctive relief. ${ }^{285}$ In cases where no "tangible employment actions" have taken place, the Supreme Court has acknowledged a two-prong affirmative defense to sexual harassment claims. ${ }^{286}$ Pursuant to that defense, an employer can avoid liability by demonstrating (1) "that the employer exercised reasonable care to prevent and correct promptly any sexually harassing behavior" and (2) "that the plaintiff employee unreasonably failed to take advantage of any preventive or corrective opportunities provided by the employer or to avoid harm otherwise." ${ }^{287}$ Written antiharassment policies with grievance procedures are not per se necessary for the defense; however, they speak strongly to the first element. ${ }^{288}$ Further, if the employer can demonstrate the affected employee failed to take advantage of such a policy, it will typically be enough to fulfill the second prong. ${ }^{289}$ Although courts - and later Congress-acknowledged the possibility of hostile work environment claims absent adverse employment actions, thoughtful employer policies may serve as defenses in these kinds of cases.

\section{ADA's and GINA's Privacy Provisions}

Hostile work environment doctrine demonstrates how judges have expanded what constitutes an employment discrimination harm. Legislators could likewise create new kinds of antidiscrimination harms. Congress has already expanded the statutory definition of discrimination past the adverse employment action on at least two occasions: the ADA's medical examination provisions and GINA's privacy protection.

Under the ADA, an employer cannot "conduct a medical examination or make inquiries of a job applicant as to whether such applicant is an individual with a

284. 1 John F. Buckley IV \& Michael R. Lindsay, Defense of Equal Employment Claims $§ 3: 57$ (2015).

285. See 42 U.S.C. $§ 1981$ A (2012); see also Civil Rights Act of 1991, Pub. L. No. 102-166, $\S 3(1), 105$ Stat. 1071 (codified as amended in scattered sections of 42 U.S.C.) (explaining that one purpose of the Civil Rights Act of 1991 was "to provide appropriate remedies for intentional discrimination and unlawful harassment in the workplace ...").

286. Faragher v. City of Boca Raton, 524 U.S. 775, 807 (1998); see also Burlington Indus. v. Ellerth, 524 U.S. 742, 748 (1998); Sturm, supra note 4, at 481-82.

287. Burlington Indus., 524 U.S. at 765.

288. Id. ("While proof that an employer had promulgated an antiharassment policy with complaint procedure is not necessary in every instance as a matter of law, the need for a stated policy suitable to the employment circumstances may appropriately be addressed in any case when litigating the first element of the defense.").

289. Id. ("And while proof that an employee failed to fulfill the corresponding obligation of reasonable care to avoid harm is not limited to showing an unreasonable failure to use any complaint procedure provided by the employer, a demonstration of such failure will normally suffice to satisfy the employer's burden under the second element of the defense."). 
disability or as to the nature or severity of such disability." ${ }^{290}$ After an employer extends an offer, the employer may require the applicant to submit to a medical entrance exam. ${ }^{291}$ As soon as the employee begins work, the employer is again forbidden from requiring a medical exam or asking about the presence or severity of the employee's disability, unless the exam or inquiry is job related and consistent with business necessity. ${ }^{292}$ Furthermore, unlike the statute's other protections, courts have applied the ADA's prohibition on medical examinations to employees with and without disabilities. ${ }^{293}$ Claimants do not have to prove the threshold requirement of being a person with a disability that is necessary for the statute's other provisions. ${ }^{294}$ While the ADA contains provisions that bar inquiries and prohibit discrimination, it does not indicate what constitutes appropriate relief for cases when there is no adverse employment action. Plaintiffs have managed to obtain injunctive relief for inappropriate medical inquiries, ${ }^{295}$ yet they may have to establish a cognizable injury to receive damages. ${ }^{296}$

Thus, with the exception of the very specific job- or safety-related circumstances, discussed in Part IV.C, the ADA forbids employers from asking about their employees' disabilities, regardless of whether those individuals actually have disabilities. Importantly, those inquiries constitute discrimination within the meaning of the statute despite the absence of an adverse employment action.

The Genetic Information Nondiscrimination Act (GINA), however, offers even more robust protection. In addition to GINA's antidiscrimination protection described in Part I, the statute also prohibits employers from obtaining genetic information, stating that they cannot "request, require, or purchase genetic information with respect to an employee or a family member of the employee." 297 While the statute carves out some exceptions for the valid acquisition of genetic information by employers, ${ }^{298}$ unlike the ADA, GINA does not permit conditional offers.

The ADA's and GINA's privacy provisions, therefore, indicate Congress's willingness to protect against discrimination in circumstances when an adverse employment action has not occurred.

290. 42 U.S.C. $\S 12112(d)(2)(A)(2012)$.

291. See infra note 318 and accompanying text.

292. 42 U.S.C. $\S 12112(d)(4)(A)$.

293. See, e.g., Conroy v. N.Y. State Dep't of Corr. Servs., 333 F.3d 88, 95 (2d Cir. 2003).

294. See supra note 34 and accompanying text.

295. See Barnes v. Cochran, 944 F. Supp. 897 (S.D. Fla. 1996) (holding that the employer had legitimate nondiscriminatory reasons for hiring but enjoining it from future medical inquiries).

296. See Armstrong v. Turner Indus., 141 F.3d 554, 562 (5th Cir. 1998).

297. 42 U.S.C. $\S 2000 f f-1$ (b) (2012). Like the ADA, GINA does not provide different remedies for its privacy and antidiscrimination provisions. The issue of damages for violations of GINA's privacy provisions remains hazy. The statute provides that Title II litigants can recover the same compensatory and punitive damages that are provided under the Civil Rights Act. See id. § 2000ff-6(a); 29 C.F.R. § 1635.10(b)(1) (2015). However, the privacy provision is unique to GINA, meaning that the remedies created for the antidiscrimination harms protected by the Civil Rights Act are designed for adverse employment actions and not inquiries related to protected status.

298. See 42 U.S.C. $\S \S 2000 f f-1(b)(1)-(5)$. 


\section{State Law}

In addition to GINA and the ADA, several state legislatures have explicitly banned employers from asking about protected status in certain circumstances, mainly pre-employment. Approximately twenty-five states have such legislation. ${ }^{299}$ California's version provides:

It is an unlawful employment practice, unless based upon a bona fide occupational qualification, or, except where based upon applicable security regulations established by the United States or the State of California ... . For any employer or employment agency ... to make any non-job-related inquiry of an employee or applicant, either verbal or through use of an application form, that expresses, directly or indirectly, any limitation, specification, or discrimination as to race, religious creed, color, national origin, ancestry, physical disability, mental disability, medical condition, genetic information, marital status, sex, gender, gender identity, gender expression, age, sexual orientation, or military and veteran status . ... 300

While the California law prohibits pre-employment inquiries that indicate a possible discriminatory motive, the statute's interpretative regulations prohibit any question by an employer that could identify the applicant's protected status. ${ }^{301}$ The California Department of Fair Employment and Housing publishes a pamphlet for employers in conjunction with its prohibition on pre-employment inquiries. ${ }^{302}$ The Department advises employers not to inquire into myriad things. The list of unacceptable inquiries, not surprisingly, includes subjects like race, sex, national origin, religion, age, and disability. ${ }^{303}$ Yet in addition to these very clear examples of protected status, the pamphlet also warns employers not to ask questions related to when a person graduated, a person's hair, eye color, or complexion, and questions about general health. ${ }^{304}$ While the statutory language is narrow, the implementing regulations give the prohibition on pre-employment inquiries far wider breadth. Identical to its federal counterparts, the California statute does not distinguish between remedies for improper inquiries and remedies for adverse employment actions. ${ }^{305}$

299. Among the states limiting an employer's ability to inquire about protected status pre-employment are Alaska, Arizona, California, Colorado, Hawaii, Idaho, Illinois (by regulation), Kansas, Maine, Massachusetts, Michigan, Minnesota, Missouri, Nevada, New Hampshire, New Jersey, New Mexico, New York, Ohio, Oklahoma, Pennsylvania, Rhode Island, Utah, Washington, West Virginia, and Wisconsin. See 1 LEX. K. LARsON \& THEOdORE F. Shults, EMPLOYMENT SCREENING § 11 (2015).

300. CAL. Gov'T CoDE $\S 12940(d)$ (West 2015).

301. See CAL. Code REgS. tit. 2, § 11016(b)(1) (2015) ("Inquiries that directly or indirectly identify an individual on a basis enumerated in the Act are unlawful unless made pursuant to a permissible defense.").

302. See CAl. Dep't of FAir Emp't And Hous., Employment Inquiries, available at http://www.dfeh.ca.gov/res/docs/Publications/DFEH-161.pdf [http://perma.cc/QLP7-FLXY].

303. Id.

304. Id.

305. Id. 
As mentioned, even absent outright legal prohibitions, it is a widely accepted best practice for employers not to ask about protected status, lest those inquiries be used to establish evidence of discrimination in the event of an adverse employment action. ${ }^{306}$ While this general norm against inquiries into protected status may do some work to combat the potential for stereotype threat in employment, it fails to do enough. First, it only targets one potential type of stereotype threat trigger. Second, such policies tend to be emphasized at the application stage, encouraging employers not to ask about protected status during interviews ${ }^{307}$ and failing to extend into actual employment. Third, because the questions themselves are by and large not independently legally actionable, the employee must wait until an adverse employment action has occurred and a stereotype threat has, perhaps, already done its damage.

Like the hostile work environment doctrine and the ADA and GINA, these statutes demonstrate that lawmakers are willing to protect employees from more than just adverse employment actions in the effort to end discrimination.

\section{B. Tensions}

While conduct that activates stereotype threat may lead to welfare reductions, inquiries related to protected status could achieve important goals such as workplace safety, diversity, and accommodation. Consequently, expanding the notion of an employment discrimination harm, through either statute or common law, should also provide a series of exceptions or potential defenses to ensure that it does not chill socially valuable employer conduct.

\section{Job-Related Inquiries and Workplace Safety}

Sometimes an individual's protected status will impact her ability to do a particular job. Current federal employment discrimination statutes account for circumstances in which an individual's protected status renders her unqualified for the job or unable to perform the job safely. When an employer asks about protected status for valid qualification or workplace safety reasons, those inquiries are not yet harmful.

One way in which employment discrimination legislation ensures that employers will not be forced to hire unqualified individuals is the bona fide occupation qualification (BFOQ) defense. ${ }^{308}$ Pursuant to a BFOQ defense, there are some qualities that - while normally would constitute discrimination when considered-are necessary for performing certain jobs. Thus, BFOQs allow employers to intentionally take protected status into account under limited circumstances. Both Title VII and the ADEA contain such provisions. ${ }^{309}$ Title VII's BFOQ provision reads:

306. See supra note 244 and accompanying text.

307. See supra note 244 and accompanying text.

308. 29 U.S.C. $§ 623(f)(1)(2012) ; 42$ U.S.C. $§ 2000 \mathrm{e}-2(\mathrm{e})$ (2012); see also 1 LARSON \& SHULTZ, supra note 299 , at $\$ 11.02$.

309. 29 U.S.C. $\S 623(f)(1) ; 42$ U.S.C. $\S 2000 \mathrm{e}-2(\mathrm{e})$. 
[I]t shall not be an unlawful employment practice for an employer to hire and employ employees ... on the basis of [their] religion, sex, or national origin in those certain instances where religion, sex, or national origin is a bona fide occupational qualification reasonably necessary to the normal operation of that particular business or enterprise $\ldots .{ }^{310}$

Although employers may assert a BFOQ defense with respect to religion, sex, or national origin, they may not do so with respect to race. ${ }^{311}$ Courts have permitted BFOQs in Title VII suits, most frequently in the context of sex discrimination, for reasons related to privacy (e.g., hiring only female corrections officers for a women's prison to preserve the dignity of the prison's inmates), safety (e.g., prohibiting pregnant flight attendants because of their diminished ability to perform the necessary actions in the case of an emergency), and authenticity (e.g., allowing the hiring of performers or actors of one sex). ${ }^{312}$ Similarly, the ADEA's BFOQ section provides:

It shall not be unlawful for an employer, employment agency, or labor organization . . . to take any action otherwise prohibited under subsections (a), (b), (c), or (e) of this section where age is a bona fide occupational qualification reasonably necessary to the normal operation of the particular business, or where the differentiation is based on reasonable factors other than age . ... .313

In the context of age, a valid BFOQ would be a mandatory retirement age for school bus drivers for reasons related to public safety. ${ }^{314}$ Like its federal counterparts, California's state employment discrimination statute and its accompanying regulations allow for BFOQs, as well as defenses of business necessity and job-relatedness. ${ }^{315}$

310. 42 U.S.C. $\S 2000 \mathrm{e}-2(\mathrm{e})$.

311. Id.

312. See Katie Manley, The BFOQ Defense: Title VII's Concession to Gender Discrimination, 16 DUKE J. GENDER L. \& POL'y 169, 176-82 (2009) (discussing successful uses of the BFOQ defense).

313. 29 U.S.C. $\S 623(f)(1)$.

314. See, e.g., Maki v. Comm'r of Educ., 568 F. Supp. 252 (N.D.N.Y. 1983) (upholding a mandatory retirement age for school bus drivers). But see Tullis v. Lear Sch., Inc., 874 F.2d 1489 (11th Cir. 1989) (striking down a mandatory retirement age for school bus drivers because the school failed to present evidence to support a BFOQ).

315. See CAL. Gov'T CODE $\S 12940(d)$ (West 2011) ("This part does not prohibit an employer or employment agency from inquiring into the age of an applicant, or from specifying age limitations, where the law compels or provides for that action."); CAL. CODE REGS. tit. 2, § 11010 (2015) (“(a) Bona Fide Occupational Qualification (BFOQ). Where an employer or other covered entity has a practice that on its face excludes an entire group of individuals on a basis enumerated in the Act (e.g., all women or all individuals with lower back defects), the employer or other covered entity must prove that the practice is justified because all or substantially all of the excluded individuals are unable to safely and efficiently perform the job in question and because the essence of the business operation would otherwise be undermined. (b) Business Necessity. Where an employer or other covered entity has a facially neutral practice that has an adverse impact (i.e., is discriminatory in effect), the employer or other covered entity must prove that there exists an overriding legitimate business 
The ADA also contains certain provisions designed to guarantee that complying with the statute does not require employers to hire people who cannot perform the job safely. For example, Title I limits most of its protections to "qualified individuals" with disabilities, that is, people with disabilities "who, with or without reasonable accommodation, can perform the essential functions" of the job in question. ${ }^{316}$ Additionally, employers can make pre-employment job-related inquiries $^{317}$ and, as mentioned, following the initial hiring process, employers may condition their final offers on medical screenings of their potential employees but only when those screenings are (1) job-related, (2) imposed uniformly, and (3) kept confidential. ${ }^{318}$ If an employer chooses not to hire an individual based on her inability to meet a qualification standard, that qualification standard must be job-related and consistent with business necessity. ${ }^{319}$ Finally, the ADA offers a direct threat defense that allows employers not to hire an individual with a disability when employing that individual would pose "a significant risk of substantial harm to the health or safety of the individual or others that cannot be eliminated or reduced by a reasonable accommodation." ${ }^{320}$ The ADA, therefore, has several mechanisms for ensuring that employers can consider disability when it is relevant to performing the job in question.

Even GINA, with its outright ban on requests for genetic information, allows employers some leeway for obtaining genetic information when safety is a concern. The law provides an exception that allows employers to request genetic information to genetically monitor the biological effects of toxic substances. ${ }^{321}$ Yet to qualify for this exemption, the employer must comply with a number of very specific procedural conditions, including, but not limited to, written notice to the employee, written authorization from the employee, informing the employee of the results, and compliance with other federal employment monitoring statutes and regulations. ${ }^{322}$ The statute also allows employers to request genetic information in conjunction with wellness programs, to comply with family and medical leave laws, and for forensic quality control purposes. ${ }^{323}$ (GINA also includes exceptions for incidental acquisition. ${ }^{324}$ )

purpose such that the practice is necessary to the safe and efficient operation of the business and the challenged practice effectively fulfills the business purpose it is supposed to serve. The practice may still be impermissible where it is shown that there exists an alternative practice that would accomplish the business purpose equally well with a lesser discriminatory impact. (c) Job-Relatedness. See section 11017(e) for the defense of job-relatedness, which is permissible in employee selection cases.").

316. 42 U.S.C. § 12111(8) (2012); see also 29 CFR §1630.3 (defining "qualified individual with a disability").

317. 42 U.S.C. $\S 12112(d)(2)(B)(2012)$.

318. 42 U.S.C. $\S \S 12101-12213(2012)$.

319. 42 U.S.C. $\S 12112$ (b)(6) (2012); see also 42 U.S.C. § 12113(a) (2012).

320. 29 C.F.R. $\$ 1630.02$ (2012); see also 42 U.S.C. $\S 12111(3)$.

321. 42 U.S.C. $\S 2000 f f-1(b)(5)$ (2012).

322. See id.

323. 42 U.S.C. § 2000ff-1(b)(2) (2012); 42 U.S.C. § 2000ff-1(b)(3) (2012); 42 U.S.C. § 2000ff-1(b)(6) (2012).

324. 42 U.S.C. $§ 2000 f f-1(b)(1)$ (2012); 42 U.S.C. $§ 2000 f f-1(b)(4)$ (2012). 
Interestingly, by failing to include defenses for job-relatedness, accommodation, or direct threat, GINA may actually go too far. Take, for example, recent lawsuits against employers for asking applicants and employees to provide family histories and other medical information. ${ }^{325}$ Certain aspects of family history may relate to a job when an individual's health affects her ability to perform that job's essential functions. Moreover, health-related information could affect whether an individual is qualified. Arguably, such inquiries-while implicating genetic information as defined by the statute - are not the kinds of requesting or requiring of genetic information that Congress sought to outlaw. 326

GINA is more stringent than the ADA, which allows post-offer medical testing in certain limited circumstances. However, as Mark Rothstein has pointed out, it is practically impossible to separate genetic information from other kinds of health-related information. ${ }^{327}$ For example, because GINA covers family history, it prohibits certain inquiries that would be allowable under the ADA. It would make sense to at least reconcile GINA with the ADA to permit limited, job-related medical

325. See, e.g., EEOC v. Nestle Prepared Foods, No. 5:11-mc-358-JMH-REW, 2012 WL 1888130 (E.D. Ky. May 23, 2012) (challenging a family medical history questionnaire given by a private physician as part of a fitness-for-duty evaluation). Employers can still make certain requests for medical information. The EEOC regulations provide that the acquisition of genetic information in response to a request for medical information will be deemed inadvertent if the employer includes the following language in its request:

The Genetic Information Nondiscrimination Act of 2008 (GINA) prohibits employers and other entities covered by GINA Title II from requesting or requiring genetic information of an individual or family member of the individual, except as specifically allowed by this law. To comply with this law, we are asking that you not provide any genetic information when responding to this request for medical information. "Genetic information," as defined by GINA, includes an individual's family medical history, the results of an individual's or family member's genetic tests, the fact that an individual or an individual's family member sought or received genetic services, and genetic information of a fetus carried by an individual or an individual's family member or an embryo lawfully held by an individual or family member receiving assistive reproductive services.

29 C.F.R. $\S 1635.8(b)(1)(i)(B)$ (2011). However, even this disclaimer acknowledges that requests for family history are still requests for genetic information thereby running afoul of the statute. Fire and police departments that request family history in conjunction with their work-related medical inquiries thereby violate GINA.

326. Congress was primarily interested in discrimination on the basis of genetic test results. GINA's findings state that

[F]ederal legislation establishing a national and uniform basic standard is necessary to fully protect the public from discrimination and allay their concerns about the potential for discrimination, thereby allowing individuals to take advantage of genetic testing, technologies, research, and new therapies.

The Genetic Information Nondiscrimination Act of 2008 2(5), 42 U.S.C. § $2000 \mathrm{ff}$.

327. Mark A. Rothstein, GINA, the ADA, and Genetic Discrimination in Employment, 36 J.L. MED. \& ETHICS 837, 837-38 (2008). 
inquiries following conditional offers of employment. ${ }^{328}$ GINA demonstrates that while prohibiting inquiries into protected status may serve antidiscrimination goals, those provisions, if drawn too broadly, can restrict an employer's ability to make important job- and safety-related determinations. In addition, GINA demonstrates the shortcomings of a strict liability approach for expanding employment discrimination harms.

Taken together, the BFOQ defenses of Title VII and the ADEA; the ADA's qualification requirement, post-offer medical screening provision, and direct threat defense; and even GINA's exception for occupational monitoring, all indicate that protected status may at times be related to adequately performing a particular job. Construing stereotype threat triggers as harmful must therefore account for when the protected status is relevant to being able to safely and effectively execute the essential functions of the job.

\section{Antidiscrimination Purpose}

Also, while perhaps counterintuitive, certain conduct that could trigger stereotype threat may at times be essential for achieving antidiscrimination objectives. The two primary examples of antidiscrimination actions that require information related to protected status are diversity initiatives and reasonable accommodation requirements. If an employer seeks information pertaining to protected status for antidiscrimination purposes, it should not be actionable. Existing federal employment discrimination statutes allow some degree of positive differential treatment when the goal is to target subordination. ${ }^{329}$

For example, while Title VII prohibits discrimination on the basis of race, sex, or national origin, the statute's EEOC regulations allow for the consideration of those traits when done with the purpose of addressing past discrimination. They provide that affirmative action is permissible under the statute when there is an "actual or potential adverse impact," an employer wishes "to correct the effects of prior discriminatory practices," or previous restrictions have artificially limited the diversity of the labor pool. ${ }^{330}$ To establish an affirmative action program, an employer must engage in a

328. Importantly, any inquiries into genetic information by employers should be directly job-related to avoid needlessly invading genetic privacy and opening employees up to genetic-information discrimination. See Sharona Hoffman, Preplacement Examinations and Job-Relatedness: How to Enhance Privacy and Diminish Discrimination in the Workplace, 49 U. KAN. L. REV. 517, 520 (2001).

329. Notably, GINA's prohibition on inquiries about genetic information contains no exceptions for antidiscrimination-driven positive differential treatment. I have therefore argued in favor of relaxing that provision to allow diversity initiatives and reasonable accommodations. See Roberts, supra note 116, at 634-47.

330. 29 C.F.R. $\S 1608.3$ (2014). California's state employment discrimination regulations also allow for affirmative action. See CAL. CoDE REGS. tit. 2, § 11016(a)(1) (2015) (providing that "nothing in these regulations shall preclude affirmative efforts to utilize recruitment practices to attract minorities, individuals of one sex or the other, individuals with disabilities, individuals over 40 years of age, and any other individual covered by the Act"); see also CAL. CODE REGS. tit. 2, § 11010(e) (2015) (allowing valid affirmative action programs as a defense to discrimination under the statute). 
"reasonable self analysis," "a reasonable basis for concluding action is appropriate," and "reasonable action." ${ }^{331}$ Given the antidiscrimination purpose of affirmative action programs such as diversity initiatives, it would not make sense to construe those programs as harmful.

The ADA also allows for positive differential treatment, albeit in a different capacity. Title I provides that an employer's failure to make a reasonable accommodation, an action designed to make the workplace more accessible to the employee with the disability ${ }^{332}$ but that does not impose an undue hardship on the employer, ${ }^{333}$ constitutes actionable discrimination. ${ }^{334}$ Recall that, once an individual has been hired, her employer cannot inquire about the presence, nature, or severity of a possible disability. ${ }^{335}$ However, once an employee requests a reasonable accommodation, the employer and the employee must engage in a dialogue regarding how to best provide the requested accommodation. That exchange will very likely require the employer to ask the employee questions about her disability, which could in turn trigger stereotype threat. But because those inquiries are essential to the reasonable accommodation process and the statute's goal to eliminate discrimination on the basis of disability, the clear benefit would outweigh any potential harm from stereotype threat.

Finally, the EEOC requires employers to collect and submit demographic data about their employees with an eye to catching potential discrimination. ${ }^{336}$ While this

331. 29 C.F.R. $§ 1608.4$. The California regulations also adopt the EEOC approach. See CAL. Code Regs. tit. 2, § 11011 (2015) ("Voluntary action by employers and other covered entities is an effective means for eliminating employment discrimination. The Council hereby adopts the Affirmative Action Guidelines of the federal Equal Employment Opportunity Commission (EEOC).").

332. Pursuant to the ADA, reasonable accommodations include "making existing facilities used by employees readily accessible to and usable by individuals with disabilities" and "job restructuring, part-time or modified work schedules, reassignment to a vacant position, acquisition or modification of equipment or devices, appropriate adjustment or modifications of examinations, training materials or policies, the provision of qualified readers or interpreters, and other similar accommodations for individuals with disabilities." 42 U.S.C. § 12111(9) (2012).

333. An "undue hardship" is "an action requiring significant difficulty or expense." 42 U.S.C. $\S 12111(10)(\mathrm{A})$.

334. 42 U.S.C. $\S 12112(5)$ (2012). The law requires employers to provide reasonable accommodations both to applicants and to current employees and expressly provides that the denial of an employment benefit in order to avoid having to provide a reasonable accommodation is discriminatory. $I d$. (“(A) not making reasonable accommodations to the known physical or mental limitations of an otherwise qualified individual with a disability who is an applicant or employee, unless such covered entity can demonstrate that the accommodation would impose an undue hardship on the operation of the business of such covered entity; or (B) denying employment opportunities to a job applicant or employee who is an otherwise qualified individual with a disability, if such denial is based on the need of such covered entity to make reasonable accommodation to the physical or mental impairments of the employee or applicant ....”).

335. See supra note 292 and accompanying text.

336. The EEOC collects data from employers with over one hundred employees. These EEOC reporting requirements are mandatory. See EEO Reports/Surveys, EEOC http://www.eeoc.gov/employers/reporting.cfm [http://perma.cc/ZR7Z-44VU]. 
practice inevitably requires employers to discuss the protected statuses of their employees, it does so for a distinctly antidiscrimination purpose.

Nevertheless, even when done for antidiscrimination purposes, differential treatment could still trigger stereotype threat. A recent study confirms this possibility, finding that affirmative action can impede high-ability women's performance on complex math tests. ${ }^{337}$ As a result, employers who implement diversity initiatives or provide accommodation should acquaint themselves with the literature on stereotype threat to avoid its negative outcomes as much as possible.

Summing up, rethinking employment discrimination harms should not entail a blanket expansion of the existing antidiscrimination statutes to cover all potential stereotype triggers. In particular, certain actions - while running the risk of activating stereotype threat — nonetheless serve important, non-discriminatory goals and should remain intact but with the appropriate adjustments.

\section{Role of Law in Decreasing Stereotype Threat}

In advocating that employment discrimination law go beyond the adverse employment action to address stereotype threat, this Article does not propose one singular way of accomplishing that end. However, the law can intervene to mitigate the effect of stereotype threat. Kang and Lane have identified four possible metrics for intervention with respect to implicit bias: (1) ex-post specific (individual litigation), (2) ex-post general (redressing structural disparities), (3) ex-ante specific (analysis of particular disparities within a system), and (4) ex-ante general (adoption of rules and policies to prevent discriminatory conduct). ${ }^{338}$ These same kinds of interventions could be likewise valuable with regard to stereotype threat. Acknowledging stereotype threat triggers as harmful could possibly offer relief along the lines of hostile work environment jurisprudence. However, recognizing the role of stereotype threat might do the most good ex-ante by creating incentives for employers to self-evaluate and to adopt policies and procedures that minimize the incidence of stereotypic harms.

\section{Individual Litigation}

Hostile work environment claims provide the best model for individual litigants to challenge stereotype threat. Sturm describes a "now-common type of harassment claim" that "consist[s] of undermining women's perceived competence, freezing them out of crucial social interactions, or sanctioning behavior that departs from stereotypes about gender or sexual orientation." ${ }^{339}$ These actions may of course also trigger stereotype threat. Additionally, plaintiffs could raise hostile work environment claims for the presence of stereotype-relevant

337. Anat Bracha, Alma Cohen \& Lynn Connell-Price, Affirmative Action and Stereotype Threat (Harvard Law Sch. John M. Olin Ctr. Discussion Paper, Paper No. 805, 2015), available at http://papers.ssrn.com/sol3/papers.cfm?abstract_id=2563772 [http://perma.cc /WZN5-FGSP].

338. Kang \& Lane, supra note 8 , at 492-503.

339. Sturm, supra note 4, at 468-69. 
materials on the job. For example, a male-dominated workplace that includes sexualized depictions of women, like pornographic photographs or "pinup" calendars, might also be considered discriminatory because those materials communicate the message that women are outsiders. ${ }^{340}$ Again, this conduct might also activate stereotype threat.

Sturm provides an example of such hostile work environment claims when describing second-generation discrimination. She asks the reader to consider a law firm that aggressively recruits women - such that almost half of its associates are female — but that fails to promote or retain its female employees. ${ }^{341}$ She describes the resulting claims as follows:

The complaints involve a range of issues: differences in patterns of work assignment and training opportunities among men and women; tolerance of a sexualized work environment by partners who are otherwise significant "rainmakers"; routine comments by male lawyers, particularly in predominantly male departments, on the appearance, sexuality, and competence of women; harsh assessments of women's capacities and work styles based on gender stereotypes; avoidance of work-related contact with women by members of particular departments; and hyper-scrutiny of women's performance by some, and the invisibility of women's contributions by others. These complaints coincide with a concern about low morale and productivity among diverse work teams. ${ }^{342}$

While Sturm does not describe it as such, the low morale and productivity could be due in part to the effects of stereotype threat. This relatively new breed of hostile work environment claim appears to give some legal recourse for certain types of stereotype threat-related harms.

Practically speaking, hostile work environment doctrine may not be as useful as initially appears. To start, these types of claims are particularly complex: the amorphous and variable nature of the harms renders clear rules and one-size-fits-all remedies frustratingly elusive. ${ }^{343}$ Additionally, the Supreme Court has set a very high standard for these claims, asking whether the situation is "hostile" or "abusive." "344 In making these determinations, the courts look to a variety of factors, such as "the frequency of the discriminatory conduct; its severity; whether it is physically threatening or humiliating, or a mere offensive utterance; and whether it unreasonably interferes with an employee's work performance." ${ }^{345}$ Thus, much of the actions that activate stereotype threat could be dismissed as stray remarks, as described earlier in Part IV.A. ${ }^{346}$ Furthermore, even if an employer's conduct impedes the affected worker's performance, the employee will only have a claim if that interference is unreasonable. Consequently, courts and litigants alike will not

340. Green, supra note 40, at 132-33.

341. Sturm, supra note 4 , at 469-70.

342. Id. at 470 .

343. Id. at 469.

344. Harris v. Forklift Sys., Inc., 510 U.S. 17, 23 (1993).

345. Id.

346. See supra note 261 and accompanying text. 
recognize a wide range of conduct that affects opportunities and job performance as being discriminatory under a hostile work environment theory. ${ }^{347}$ Courts have therefore imposed a more robust standard of analysis than the language of the statute, which only asks whether the employer's conduct affects the terms and conditions of employment, would seem to require. ${ }^{348}$

Moreover, while potentially covering stereotype threat triggers, the current status of hostile work environment does not account for the negative impact those triggers might have on employment. To raise the kinds of claims outlined above, a litigant must continue performing to the best of her abilities despite the hostile work environment. She must simply wait for enough negative conduct to accrue to file suit but without a significant enough drop in performance to warrant a justifiable adverse employment action. This reality poses a Goldilocks dilemma: by the time the employer's conduct becomes severe and pervasive enough to be legally actionable, the stereotype threat will have done its damage and the employee will be underperforming and vulnerable to seemingly meritocratic adverse employment actions. While hostile work environment claims may at first blush seem like a promising avenue for combatting stereotype threat, at present they fail to provide a meaningful remedy. Providing proper relief for the harms of stereotype threat would require a substantial overhaul of our current hostile work environment doctrine.

\section{Structural Disparities}

Ex-post interventions can also occur on the general level as structural solutions. Kang and Lane explain that ex-post, general interventions can take at least two forms: (1) social framework evidence and (2) structural litigation. ${ }^{349}$ In the first instance, an individual litigant could use the generalized literature of stereotype threat to argue she faced discrimination, not unlike how Ann Hopkins used research on sex stereotyping to establish her gender discrimination claim in the famous case Price Waterhouse v. Hopkins. ${ }^{350}$ Additionally, litigants could use stereotype threat research to challenge structural features that generate workplace disparities. ${ }^{351}$ For instance, pattern or practice claims are designed to address aggregate discrimination. ${ }^{352}$ Such cases begin by identifying a group disparity and policy that could be causing them. ${ }^{353}$ The burden then shifts to the employer to offer a nondiscriminatory reason for the inequality. ${ }^{354}$ If it cannot, the court may conclude the inequity is the result of discrimination. ${ }^{355}$ However, these cases are relatively rare

347. Green, supra note 40, at 135.

348. Sperino, supra note 42 , at 87.

349. Kang \& Lane, supra note 8, at 493-98.

350. Id. at 494 .

351. Id. at $495-98$.

352. Amy L. Wax, Supply Side or Discrimination? Assessing the Role of Unconscious Bias, 83 TEMPLE L. REV. 877, 882 (2011).

353. Id.

354. Id.

355. Id. 
and tend to be difficult to win, as courts are increasingly aware of alternative reasons for disparities and are, therefore, hesitant to make a finding of discrimination. ${ }^{356}$

\section{Assessing Disparities}

In addition to the after-the-fact interventions, the law could also facilitate ex-ante strategies for combatting stereotype threat. On the specific level, an employer could monitor the workplace for discriminatory effects.

In Sturm's hypothetical discriminatory law firm, she mentions that the firm conducts an examination and "discovers dramatic differences in the retention and promotion rates of men and women in the firm." 357 Unearthing such disparities would attune the employer to the possibility of discrimination. Employers could therefore attempt to identify the areas vulnerable to stereotype threat in an effort to avoid future harmful outcomes. However, because the findings of a monitoring system might form the foundation for future litigation, the accompanying legal framework must encourage employers to identify and correct disparities and to learn from the efforts of similar types of organizations without significantly increasing employers' exposure to liability. ${ }^{358} \mathrm{Kang}$ and Lane, therefore, advocate for a self-analysis privilege to insulate employers from the risk of future litigation based on the results. ${ }^{359}$ In the context of stereotype threat, an employer could implement a system to identify when and under what conditions qualified employees who are members of stereotyped groups begin underperforming.

\section{Preemptive Rules and Policies}

Finally, stereotype threat interventions could consist of general ex-ante efforts, like rules and policies designed to prevent discriminatory conduct. An employer could, therefore, take a structural approach. A structural approach consists of a number of entities, including public, private, and nongovernmental actors, working together to create infrastructures to address second-generation discrimination. ${ }^{360}$ Institutions address these issues from a problem-solving perspective. ${ }^{361} \mathrm{~A}$ regulatory solution takes the focus away from the kind of ex-post, individual relief outlined above and instead focuses on adopting internal problem-solving and dispute resolution procedures. ${ }^{362}$ Employers thereby function akin to law-making bodies. ${ }^{363}$ But, to be successful, a regulatory approach must actually address the harms of stereotype threat, not just provide processes that allow employers to avoid litigation. ${ }^{364}$ The mere presence of a complaint procedure encourages transparency,

356. Id.

357. Sturm, supra note 4 , at 470.

358. Id. at 475 .

359. Kang \& Lane, supra note 8, at 498-99.

360. Sturm, supra note 4, at 462.

361. Id.

362. Id.

363. Id. at 463 .

364. Id. at 543. 
enabling employees to report negative experiences early and creating incentives for employers to create a nondiscriminatory workplace culture. ${ }^{365}$ One could envision an employer-made complaint process that workers could use when they experience stereotype threat, in lieu of waiting until they are in a position to file a legal claim.

Employers could look to social science when adopting their policies. Research indicates that various behaviors and strategies can minimize the negative effects of stereotypes. ${ }^{366}$ Not surprisingly, some reforms designed to address implicit bias could also reduce stereotype threat. Jolls and Sunstein have proposed positive portrayals of stereotyped groups and affirmative action as efforts that employers could undertake to "debias" the workplace both directly and indirectly. ${ }^{367}$ These same tactics, which include better integration and accountability, could likewise lower the chances of activating stereotype threat by mitigating the impact of triggers like tokenism. Furthermore, experts on stereotype threat propose that when managers acknowledge and address stereotypes directly in the workplace, it can also reduce the effects of stereotype threat. ${ }^{368}$ Having both trainings and complaint procedures to target stereotype threat might reduce the potential for harm. Of course, poorly designed interventions could backfire and actually increase stereotype threat. If people experience anxiety about interactions with members of stereotyped groups, that anxiety could lead them to conform to the very stereotypes the policies would be intended to address. ${ }^{369}$ Thus, employers would have to act carefully and in accordance with specialists in social psychology and in human resources. An expansion of employment discrimination harms to cover stereotype threat could include an affirmative defense similar to the one available in hostile work environment cases to encourage employers to adopt preventative policies and procedures. ${ }^{370}$

Given the diffuse nature of stereotype threat, effectively cabining its detrimental effect might best be achieved outside the confines of traditional employment discrimination claims. As noted, the current law leaves little relief for aggrieved individuals. Hence, structural, monitoring, and preventative measures might be the best tools for expanding the notion of what constitutes an employment discrimination harm without overburdening the employer with dramatically increased liability.

365. Id. at 483 .

366. Green, supra note 40, at 147.

367. Jolls \& Sunstein, supra note 56 , at $983-88$.

368. Roberson \& Kulik, supra note 71, at 37-38; see also Block et al, supra note 12, at 591 (noting strategies for addressing stereotype threat).

369. See Bagenstos, supra note 15, at 484; see also Green, supra note 15 , at $972-73$ ("Research also suggests that racial minorities are likely to experience anxiety and fear before and during interracial interactions arising out of concerns about being judged according to stereotypes or otherwise confirming commonly held stereotypes about their group.").

370. See supra notes 286-289. 
Table 1: Legal Interventions To Reduce Effects of Stereotype Threat ${ }^{371}$

\begin{tabular}{|c|c|c|c|}
\hline & & \multicolumn{2}{|c|}{ Time Orientation } \\
\hline & & Ex post & Ex ante \\
\hline \multirow{2}{*}{ 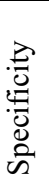 } & Specific & $\begin{array}{l}\text { I. Stereotype threat triggers as } \\
\text { legally actionable (i.e., hostile } \\
\text { work environment). }\end{array}$ & $\begin{array}{l}\text { III. Stereotype threat literature } \\
\text { as evidence in individual } \\
\text { claims; pattern or practice } \\
\text { lawsuits. }\end{array}$ \\
\hline & General & II. Self-analysis privilege. & IV. Affirmative defense. \\
\hline
\end{tabular}

After having outlined the various ways in which the law could intervene with regard to stereotype threat, it is now useful to return to the hypothetical of the female engineer whose supervisor said, "Of course you think that, you're a woman." How would the various interventions play out? As mentioned, under the current law, the engineer would likely lose her employment discrimination claim. Perhaps employment discrimination statutes could be amended or interpreted to make stereotype threat triggers independently actionable; however, such a strategy would cover so much conduct and have such a widespread chilling effect on social interactions at work that it would not be desirable. The second possibility has appeal, as it would allow the engineer to use stereotype threat literature to bolster her claim, yet she would still have difficulty establishing discrimination as a matter of law. A pattern or practice case might be a possibility if similar things happened to enough employees, but there may not be enough female engineers working at her place of employment to craft a viable claim. Moreover, the employer could cite nondiscriminatory reasons for the disparities. Creating a self-analysis privilege for workplace studies of stereotype threat might open the door for an interested employer to analyze its employees, but it would not create an incentive to encourage such studies. In other words, the engineering firm must want to measure the effect of stereotype threat and be discouraged from doing so out of fear of litigation. If the fear of having the analysis used in court is not having a chilling effect, the introduction of a self-analysis privilege would do little good. Perhaps the best option would be to create an affirmative defense to discrimination for employers that adopt policies to address stereotype threat. Such a defense would create the motivation for the engineering firm to consider how it might mitigate the effect of stereotype threat on its female employees.

Stereotype threat generates actual harm in the workplace on the basis of legally protected categories, such as race, sex, age, and disability. While current federal employment statutes fail to adequately protect against most employment discrimination harms caused by stereotype threat, existing law demonstrates a willingness to think beyond the adverse employment action. Courts and legislatures could adopt laws designed to provide relief and to encourage employers to adopt dispute resolution processes, monitoring programs, and preventative policies geared to target the harmful effects of stereotype threat.

371. This table is, of course, modeled on the table on page 492 of Kang and Lane's outstanding article. See Kang \& Lane, supra note 8, at 492. 


\section{CONCLUSION}

In 2014, Title VII celebrated its fiftieth anniversary. While much progress has been made since the original Civil Rights Act, serious disparities still persist. Traditional employment discrimination statutes such as Title VII, the ADEA, and the ADA can only do so much. While these laws may adequately target explicit, intentional discrimination on the basis of protected status, they may be unable to reach the subtle, sometimes unintended, differential treatment responsible for the continued social inequities on the basis of race, sex, age, and disability. Much has been written on the effect of cognitive functions on employers. This Article, however, explores the effect of subtle psychosocial factors on potential objects of discrimination.

One of the basic functions of the law is to redress harm. To that end, I have argued that stereotype threat triggers are in and of themselves harmful. Social psychologists have cataloged the adverse effects of stereotype threat under a number of circumstances, including at work. If employers draw attention to their employees' protected status, that conduct could activate stereotypes and, in turn, impede job performance.

Existing law provides support for recognizing employment discrimination harms that do not involve explicit adverse employment actions. Hostile work environment doctrine, the ADA, GINA, and state law provide diverse examples of how the judiciary and legislatures have provided relief for employment discrimination litigants with nontraditional kinds of claims. Expanding employment discrimination harms is not an idea that I have crafted out of whole cloth but rather is a logical extension of the existing law to better address the challenges of present-day employment discrimination. This strategy is, of course, not without its serious complexities. There are times when behaviors that could trigger stereotype threat are essential both to workplace safety and to antidiscrimination. Any attempt to extend federal employment discrimination law to cover the harms associated with stereotype threat must take account of these difficulties. To that end, legal interventions that encourage employers to be proactive are preferable to attempts to redress the harmful effects of stereotype threat after the fact. While rethinking employment discrimination harms may raise certain practical and theoretical challenges, it will nonetheless move us closer to eliminating the ongoing inequities that result from second-generation discrimination. 